Document downloaded from:

http://hdl.handle.net/10251/121813

This paper must be cited as:

Tormos, B.; Martín, J.; Carreño-Arango, R.; Ramirez-Roa, LA. (2018). A general model to evaluate mechanical losses and auxiliary energy consumption in reciprocating internal combustion engines. Tribology International. 123:161-179.

https://doi.org/10.1016/j.triboint.2018.03.007

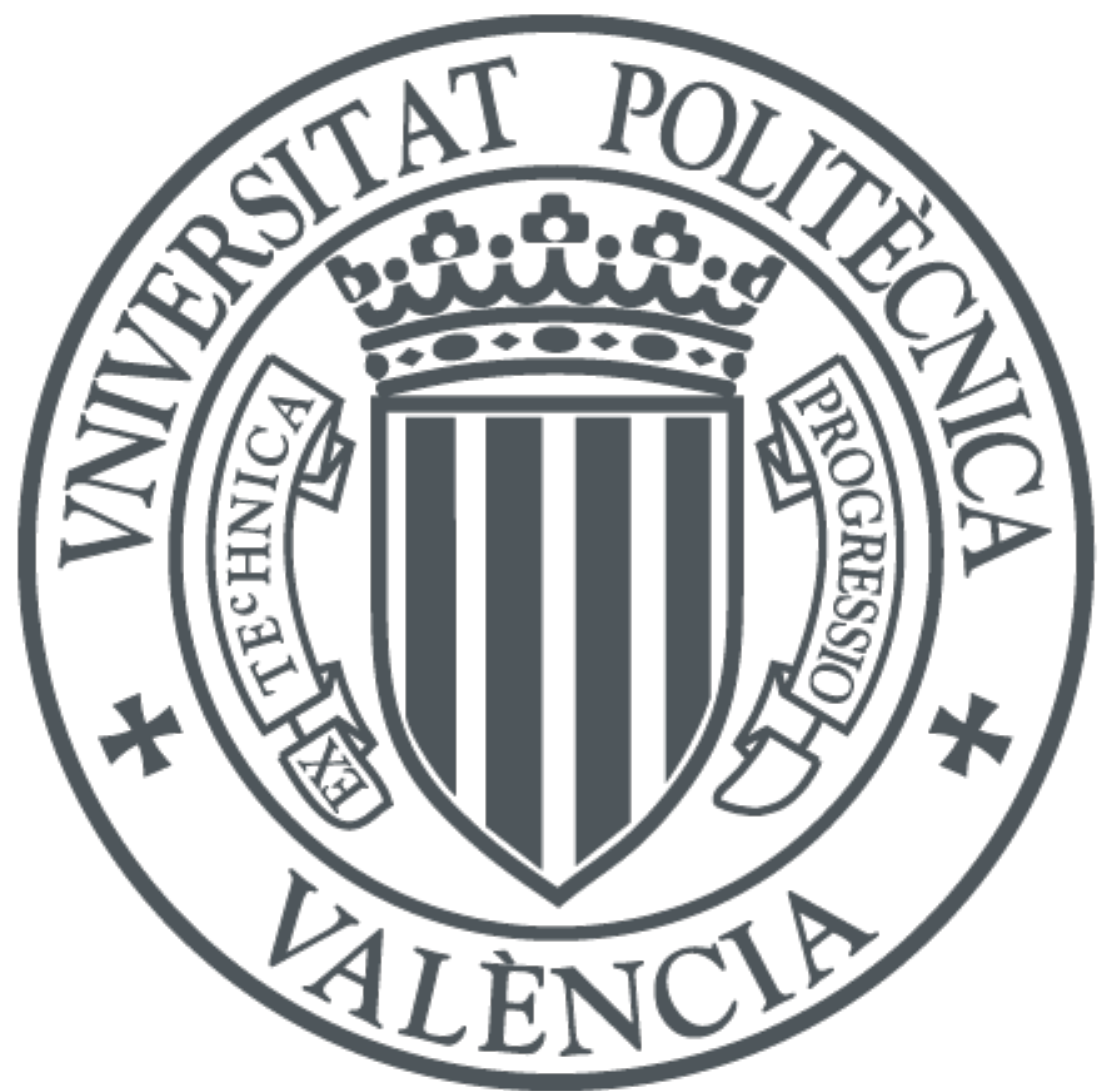

The final publication is available at

http://doi.org/10.1016/j.triboint.2018.03.007

Copyright Elsevier

Additional Information 


\title{
A general model to evaluate mechanical losses and auxiliaries energy consumption in reciprocating internal combustion engines
}

\author{
Bernardo Tormos, Jaime Martín*, Ricardo Carreño, Leonardo Ramírez \\ CMT-Motores Térmicos, Universitat Politècnica de València, Camino de Vera s/n, 46022, Valencia, Spain
}

\begin{abstract}
The increasingly stringent internal combustion engines emissions regulations, the extended use of after-treatment systems, the climatic change as consequence of green house gases emissions and the decrease of fossil fuel storages, have moved the research interest towards optimization of the internal combustion engine operation with the aim of reaching the maximum efficiency possible. This renewed interest takes into account the optimization of all the engine sub-systems to reduce as much as possible the energy losses. In this framework, the evaluation and optimization of the engine mechanisms and auxiliary systems, aimed at reducing the friction and parasitic energy consumption is one common path to achieve the efficiency targets. This work is devoted to the development of a model to determine the friction losses and the auxiliary energy consumption, based on parameters usually obtained in standard test benches. This model allows the diagnosis of the sub-systems behaviour as well as the evaluation of potential improvement by replacing or redesign some parts and components. In this work, a complete description of the models to estimate friction in the piston assembly, bearings and valve train, and energy consumption of the coolant, oil and fuel pump are provided. Finally, a brief application to demonstrate the model potential in diagnosis and predictive applications is discussed.
\end{abstract}

Keywords: Mechanical Losses, Engine Friction, Consumption optimization

${ }^{*}$ Corresponding author. Tel: +34963877650 ; fax: +34963877659

Email address: jaimardi@mot.upv.es (Jaime Martín)

URL: www. cmt.upv.es (Jaime Martín) 


\section{Nomenclature}

\begin{tabular}{|c|c|}
\hline$A$ & 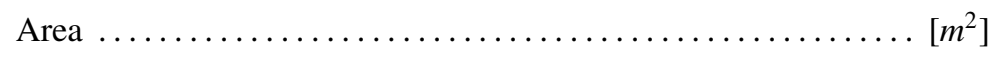 \\
\hline$a$ & 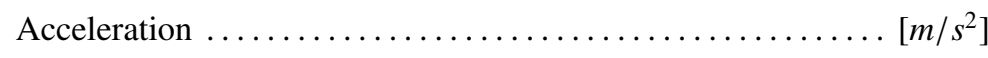 \\
\hline bmep & Brake mean effective pressure $\ldots . . .$. \\
\hline$c$ & Clearance $\ldots \ldots \ldots \ldots \ldots \ldots \ldots \ldots \ldots$ \\
\hline \multirow[t]{2}{*}{$D$} & Diameter ........ \\
\hline & Cylinder Bore...$\ldots \ldots \ldots$. \\
\hline$E$ & Young modulus $\ldots \ldots \ldots \ldots \ldots \ldots \ldots \ldots \ldots \ldots \ldots \ldots \ldots \ldots \ldots \ldots \ldots$ \\
\hline$e$ & Eccentricity $\ldots . .$. \\
\hline$f$ & Friction coefficient $\ldots \ldots \ldots \ldots$ \\
\hline$F$ & Force $\ldots \ldots$ \\
\hline$H_{v}$ & 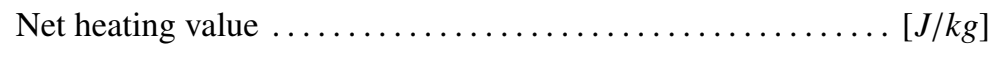 \\
\hline$h$ & Oil thickness $\ldots \ldots \ldots \ldots \ldots$ \\
\hline$J$ & Taylor parameter for bearings $\ldots \ldots \ldots \ldots \ldots \ldots \ldots \ldots$ \\
\hline$L$ & Length $\ldots \ldots \ldots \ldots$. \\
\hline$M$ & Torque $\ldots . .$. \\
\hline$m$ & Mass $\ldots \ldots \ldots \ldots \ldots$ \\
\hline$N$ & Power...$\ldots \ldots \ldots \ldots$ \\
\hline$S$ & Sommerfeld number $\ldots \ldots \ldots \ldots \ldots \ldots \ldots \ldots \ldots \ldots \ldots \ldots \ldots \ldots \ldots \ldots$ \\
\hline$n$ & Engine speed ... \\
\hline$p$ & 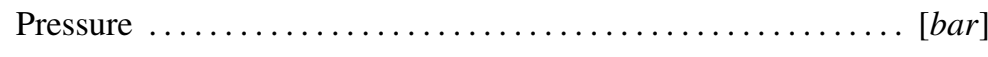 \\
\hline$T$ & Temperature ... \\
\hline$V$ & 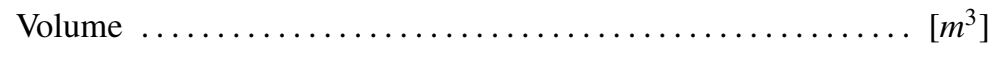 \\
\hline$v$ & $\ldots \ldots \ldots \ldots \ldots \ldots \ldots \ldots \ldots \ldots \ldots \ldots \ldots \ldots \ldots \ldots \ldots \ldots \ldots$ \\
\hline$z$ & 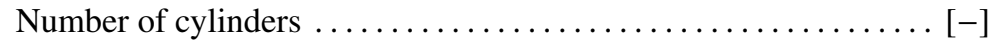 \\
\hline
\end{tabular}




\section{Greek symbols}

\begin{tabular}{|c|c|}
\hline$\alpha$ & 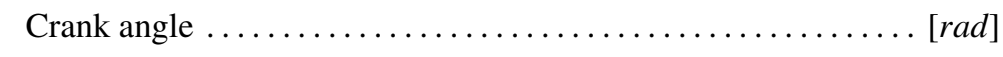 \\
\hline$\alpha_{c}$ & Pressure viscosity coefficient $\ldots .$. \\
\hline$\zeta$ & Asperities radius of curvature \\
\hline$\epsilon$ & Eccentricity ratio . \\
\hline$\eta$ & Efficiency \\
\hline$\kappa$ & Rate of change of shear stress with pressure .. \\
\hline$\lambda$ & Separation parameter $\ldots \ldots \ldots \ldots \ldots \ldots \ldots \ldots \ldots \ldots \ldots \ldots \ldots \ldots \ldots$ \\
\hline$\mu$ & Viscosity $\ldots . . .$. \\
\hline$\rho$ & Density $\ldots \ldots \ldots \ldots \ldots \ldots \ldots$ \\
\hline$\varrho$ & Asperity density $\ldots \ldots \ldots \ldots \ldots \ldots$ \\
\hline$\varphi$ & Attitude angle........... \\
\hline$\psi$ & Angle between $F_{\text {bear }}$ and $v_{o}$ \\
\hline \multirow[t]{2}{*}{$\sigma$} & Load per unit area $\ldots \ldots \ldots \ldots \ldots \ldots$ \\
\hline & Composite surface roughness parameter $\ldots \ldots \ldots \ldots \ldots \ldots[\mu m]$ \\
\hline$\tau$ & Shear stress $\ldots \ldots \ldots \ldots$ \\
\hline$\theta$ & Bearing angle $\ldots \ldots \ldots$ \\
\hline$\omega$ & 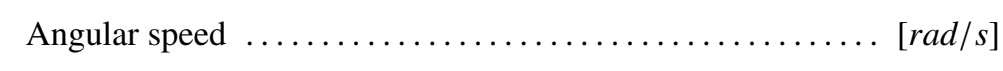 \\
\hline \multicolumn{2}{|c|}{ Subindexes } \\
\hline cam & Cam \\
\hline cool & Cooling \\
\hline fol & Follower \\
\hline$f$ & Fuel \\
\hline$r_{i}$ & Ring \\
\hline$s$ & Skirt \\
\hline sum & Oil sump \\
\hline
\end{tabular}




\section{Introduction}

In spite of the stringent emissions regulations imposed in the last years and the growing use of electric and hybrid powertrains, the Reciprocating Internal Combustion Engine (RICE) is still the most widespread technology in the automotive sector. To comply with the regulations aimed at the reduction of the $N O_{x}, H C$ and soot emissions, the engine research has been mainly focused on the limitation of pollutants formation during the combustion process and the reduction of the engine tailpipe emissions $[1,2]$. However, to accomplish with the current as well as the upcoming emissions regulations, the use of after treatment systems such as catalytic converter [3], selective catalytic reduction [4] and Diesel particulate filters [5] have become a very common solution in the automotive industry [6]. Such systems reduce effectively the emissions but penalize the fuel consumption as consequence of the exhaust gas back pressure, which increase the pumping work.

The climatic change consequence of green house gases emissions such as $\mathrm{CO}_{2}$, along with the decrease of fossil fuel storages, have moved the research interest towards optimization of RICE operation with the aim of reaching the maximum efficiency possible. Since the signing of the Kyoto protocol in 1998, the industrialized countries have been committed to binding green house gases emission reduction targets, thus, current international legislation set the new research lines, in which the reduction of $\mathrm{CO}_{2}$ is one of the most important objectives. According to the new European regulation [7], the $\mathrm{CO}_{2}$ emissions must be increasingly reduced in the upcoming years, putting even more pressure over the automotive industry.

One way to reduce the fuel consumption consists on reducing as much as possible the mechanical losses through evaluation and optimization of the mechanical systems. The mechanical losses of an engine are understood as those which reduce the gross indicated-to-brake power ratio. These are the pumping losses, the friction losses and the energy used to drive engine accesories. The pumping losses are taken into account in the indicated cycle by calculating the net indicated power; therefore, the optimization of the pumping work is closely related with the indicated cycle optimization, for instance, by using variable valve timing [8]. Therefore, this work deals with the mechanical losses which lead to energy degradation from the net indicated power to the brake power.

Friction and auxiliary losses accounts for up to $12 \%$ of the total fuel energy [9]. Regarding the relative importance of each engine sub-system in the total mechanical losses, a wide variation range can be found in the literature [10, 11], thus the pumping work ranges between $15 \%$ and $30 \%$ of the total mechanical losses, friction between $45 \%$ and $65 \%$ and auxiliary between 15 and $25 \%$. At the same time, the friction weight of each engine part is also variable depending on the source: piston rings and skirt accounts for about $40-75 \%$ of total friction, bearings between $20 \%$ and $40 \%$, and the camshaft ranges between $7 \%$ and $30 \%$. The reduction of friction and auxiliary losses leads directly to more brake power output. 
The friction level depends on the contact surfaces and lubricating oil properties. Some of the techniques used to reduce the friction are the use of smooth surfaces [12], high oil temperature [13], low viscosity oil [14] and the optimization of components design such as reducing sizes and weights of the piston, bearings and camshaft elements [15], better refinement of the piston rigs surface [16], decreasing the sealing force of the rings [17], using cam roller followers [18], decreasing the loads of valve springs [19] and substituting multiple belts for conventional V-belts [15]. All this changes are restricted by the engine operating requirements and the materials resistance, e.g. lower rings sealing forces reduce the friction between them and liner but can increase the blow-by leakage and the flow of oil from the crankcase to the combustion chamber.

The auxiliary systems of the engine are those necessary to the appropriate and safe engine operation, i.e. cooling, lubricating and injection systems. The coolant, oil and fuel pumps are usually driven by the engine crankshaft, thus the improvement of these components is key to increase the engine mechanical efficiency. The mechanically activated pumps have been designed to comply with high power requirements, which makes them inefficient at low power operating conditions. The new auxiliary systems incorporates electric pumps [20, 21, 22], variable flow pumps [23], electric valves [24] and optimized circuits [25] among others.

The evaluation of friction and auxiliary losses through modelling provides a clear insight of which systems should be improved. Moreover, with the proper model implementation, the benefits provided by using a new configuration can be evaluated. It is clear, that the development of a generally applicable model to estimate friction and auxiliary losses in RICE will facilitate the estimation, evaluation and optimization of the engine efficiency, and hence the reduction of the $\mathrm{CO}_{2}$ emissions.

This work deals with the development of a complete mechanical losses model, which allows determining and evaluating friction and auxiliary energy consumption. The model has been developed for a conventional Diesel engine, but it can be applied in any RICE after proper calibration which methodology is also included, based on parameters usually acquired in standard test benches. This makes the present model a valuable tool to any engine testing program allowing a deeper understanding of the elements/processes under study and their consequences in terms of mechanical efficiency. Finally, a brief application of the model in diagnosis and predictive applications is discussed.

\section{Methodology}

Before start with the description of the models, a short theoretical introduction will be provided, as it is necessary to understand the development procedure followed in this work. 
Strictly speaking, the mechanical losses power $\left(N_{m}\right)$ is defined as:

$$
N_{m}=N_{f r}+N_{a}+N_{p}
$$

where $N_{f r}$ is the total friction losses, $N_{a}$ is the energy consumption of auxiliary systems and $N_{p}$ is the pumping power directly determined from the indicated cycle. Note that in naturally aspirated engines $N_{p}$ is positive, thus increasing $N_{m}$ value, whilst in highly turbocharged engines $N_{p}$ could be negative, thus reducing the $N_{m}$. In a more detailed approach, the terms $N_{f r}$ and $N_{a}$ can be split as:

$$
\begin{aligned}
N_{f r} & =N_{f r, p i s}+N_{f r, b e a r}+N_{f r, v a l v} \\
N_{a} & =N_{\text {cool }}+N_{\text {oil }}+N_{f}
\end{aligned}
$$

where $N_{f r, p i s}, N_{f r, b e a r}$ and $N_{f r, v a l v}$ are the friction losses in the piston, the bearings and the valve train, and $N_{\text {cool }}, N_{\text {oil }}$ and $N_{f}$ are the energy consumption of the coolant, oil and fuel pumps.

Taking into account that experimental determination of friction and auxiliary terms cannot be performed in conventional engine test benches, they have to be indirectly determined from available experimental information along with specific sub-models. As the objective to this work is to provide a universally applicable model, both the determination and the calibration of the models for a specific engine need to be provided. Following, the main considerations to determine the friction and auxiliary are mentioned:

- In the case of the friction models, they will be determined based on lubrication and friction theories that can be found in the literature survey, as will be properly shown. As the models are theoretically determined, the model calibration requires further analysis of the experimental mechanical losses $\left(N_{m}\right)$. The calibration process will be explained later in this paper.

- In the case of the auxiliary systems, experimental data is provided by the manufacturer; therefore, the models can be developed and calibrated based on that information.

To develop a friction model, the lubrication mechanism between elements in contact has to be considered; therefore, the main lubricating regimes are following described.

\subsection{Lubrication regimes}

The lubricating regimes can be identified by means of the Stribeck diagram, presented in Figure 1. In this diagram, the friction coefficient $(f)$ in a bearing is represented as function of the Sommerfeld number $(S)$, also known as duty parameter, which is defined as:

$$
S=\frac{\mu \omega}{\sigma}
$$


where $\mu$ is the oil dynamic viscosity, $\omega$ is the rotational speed and $\sigma$ is the load per unit area.

As can be seen in Figure 1, depending on the duty parameter the main lubricating zones can be defined as boundary, hydrodynamic and mixed regime. In the first one surfaces reach direct contact, not completely separated by a lubricant hence friction losses depend directly on the material roughness and the dry contact between the surfaces, having higher friction levels than the other lubrication regimes. At hydrodynamic regime, there is a lubricant film is fully developed. This kind of lubrication occurs at stable steady operation, where the movement of the pieces constantly drag oil towards the lubricant film, thus keeping it stable. Finally, the mixed regime where asperities of the surfaces protrude through the oil film, thus some dry contact takes place between them. This occurs when the oil drag speed is low and its temperature is high, thus reducing both the viscosity and film thickness. At this regime, both boundary and hydrodynamic lubrication occurs. A special regime occurs when the lubricant between surfaces in contact is subject to sufficiently high load to elastically deform them during the hydrodynamic action. The oil viscosity increases importantly due to the high pressure, thus allowing keeping the film. This is known as elastohydrodynamic regime.

In Figure $1, S_{0}$ is the duty parameter at which transition between boundary and mixed lubrication occurs, $f_{0}$ is the dry friction coefficient during boundary lubrication, $S_{c r}$ is the critical duty parameter at which the transition between mixed and hydrodynamic lubrication occurs and $f_{c r}$ is the friction coefficient when $S=S_{c r}$.

Depending on the element analysed and the instantaneous operating condition, several lubricating regimes can take place. For the sake of simplicity, only the most significant regimes taking place of each element will be considered to calculate friction. Figure 2 shows the main lubrication zones for the elements considered in this work.

\subsection{Model development methodology}

Once the main theoretical considerations have been taken into account, the steps followed for the development, calibration and evaluation of the mechanical losses model are listed as follows:

1. Description of the experimental facility used to obtain the main parameters required by the models.

2. Development of the friction and auxiliary models.

3. Calibration and validation of the general model.

4. Analysis and Evaluation of the model performance in diagnosis and predictive applications.

\section{Experimental set-up}

The research was carried out in a DI Diesel Engine, whose main characteristics are presented in Table 1. The technical characteristics of the test cell instrumentation are presented in Table 2, and the test cell layout is shown in 
Figure 3. The installation was prepared to acquire the standard data necessary to perform the combustion diagnosis and analyse the indicated cycle, and hence to determine the experimental $N_{f r}+N_{a}$. Therefore, the in-cylinder pressure, some mean variables such as air and fuel mass flows, gas temperatures and pressures at different intake and exhaust positions and some liquids (oil and coolant) mass flows and temperatures, were measured.

To measure the in-cylinder pressure, an AVL GH13P piezo-electric transducer was installed at the glow plug hole of each cylinder. The signal provided by the piezo-electric transducer was conditioned by means of a Kistler 5011B amplifier and the digital processing was performed following the method described in [26]. In order to ensure the accuracy of the pressure signal obtained, the pressure sensor was calibrated according to the traditional method proposed in [27], and an in-house developed methodology [28] to determine some experimental and engine uncertainties (pressure pegging, top dead center position, compression ratio and so on) was applied.

The mean temperature of the gases was measured by means of K-type thermocouples, whilst the mean pressure was measured with piezo-resistive pressure transmitters. The injected fuel was measured with an AVL 733S Fuel meter, the air flow was measured with a DN80 sensiflow, the blow-by leakage, necessary to the determination of the load in the rings, was measured with an AVL blow-by Meter.

The acquisition and control of the low frequency signals (mass flows, mean pressures and temperatures) was carried out with an in-house developed software SAMARUC, which also allows visualizing the engine operation parameters, and controlling the operating conditions. The sensors signals were collected and processed in a PXI platform of National instruments. Finally, the instantaneous in-cylinder pressure signals were acquired by means of a Yokogawa DL708E Oscillographic recorder with 16 A/D converter module.

The experiments performed in this work consist on a complete swept of the engine speed and load, thus obtaining information in the whole engine map. The operating conditions are summarized in Table 3 . These measured points are used along this work for the development, calibration and validation of the mechanical losses model.

\section{Sub-models description}

\subsection{Piston rings friction losses}

The piston elements considered to be in contact with the liner are the top compression, the intermediate, the oil control rings and the piston skirt. These elements are referred henceforth as piston pack. The friction in these elements accounts for $40-75 \%$ of friction losses [29]. The seal between the liner and the rings is not perfect, thus some gas leakage occurs. This leakage produce a pressure load on the rings back-face, which increase the contact force between them and the liner, and hence the friction. The piston-rings assembly depends on the engine design, thus 
several different configuration are used in current production engines. A rather common configuration of three rings (i.e. top compression, intermediate and oil control rings) is considered for the model development.

To determine the friction of each element, it is necessary to assume some simplifications of the real operation:

- No movement of the ring in the groove is considered.

- At each crank angle $(\alpha)$, the oil film has a uniform thickness around the perimeter of the ring and it is treated as an in-compressible fluid.

- After assembled, the rings and liner are assumed to be a rigid body, thus no twist, mechanical nor thermal deformations are allowed.

- The ring's face is always in contact with the lower face of its groove.

In spite of the existence of friction models of the piston assembly that addresses some of the phenomena dismissed by the previous assumptions [30,31,32,33,34], it has to be considered the the approach of the presented model is to give a general insight of the power loss in the piston assembly rather than describe the specifics of oil transport, oil thickness variation, rings twisting and deformation among other specific phenomena out of the scope of this study.

Considering that the in-cylinder pressure is the main input of the friction model presented, the results obtained with the assumptions made are considered to be accurate enough and are in accordance with those used by other authors [35].

In Figure 4, a scheme of the loads acting on the piston pack are presented (for the sake of clearness, piston-ring interactions were omitted). The normal force $\left(F_{N, r i}\right)$ exerted on each ring is due to the gas force $\left(F_{g, r i}\right)$ applied onto the ring's back-face, and the ring's mounting force $\left(F_{m, r i}\right)$, thus:

$$
F_{N, r i}=F_{g, r i}+F_{m, r i}
$$

where $r i$ refers to the ring $i$ (i.e. $r 1$-top compression ring-, $r 2$-intermediate ring- or $r 3$-oil control ring-). $F_{g, r i}$ can be determined as function of the pressure in each groove/ring volume $\left(p_{r i}\right)$ and the ring area in contact with the gas $\left(A_{r i}\right)$ as:

$$
F_{g, r i}=p_{r i} \times A_{r i}
$$

As shown in Figure 4, $p, p_{V 2}$ and $p_{V 3}$ are the gas pressures applied in the top compression, intermediate and oil control rings respectively, being the in-cylinder pressure $(p)$ experimentally obtained, and $p_{v 2}$ and $p_{v 3}$ estimated by means of a blow-by model [36]. 
To determine the mounting force of each ring $\left(F_{m, r i}\right)$ it is necessary to know the contact pressure of the assembled ring $\left(p_{c, r i}\right)$. It is commonly calculated from the tangential $\left(F_{t, r i}\right)$ or the diametral $\left(F_{d, r i}\right)$ forces, according to Equations (7) and (8) respectively [37]:

$$
\begin{aligned}
F_{m, r i} & =2 \pi F_{t, r i} \\
& =0.9 \pi F_{d, r i}
\end{aligned}
$$

In the case of the piston skirt, it is assumed that the resulting normal force exerted over the piston is applied in the skirt. Therefore, it can be determined from the engine mechanism dynamics [36].

To determine the friction coefficient between piston pack and liner, the instantaneous lubrication regime characterized by the duty parameter has to be estimated. Since the piston has an alternative movement, some modifications have to be made in Equation (4), thus obtaining the instantaneous duty parameter for the rings $\left(S_{r i}\right)$ as follows [10]:

$$
S_{r i}(\alpha)=\frac{\pi D \mu v_{y, B}(\alpha)}{F_{N, r i}(\alpha)}
$$

where $\omega$ in Equation (4) was replaced by the instantaneous piston speed $\left(v_{y, B}\right)$ determined from the engine mechanism dynamics [36], and $\sigma$ was calculated from the load in the ring $\left(F_{N, r i}\right)$ and the contact length $(\pi D)$, following the considerations made by Taraza and Henein [10].

The friction coefficient $\left(f_{r i}\right)$ at hydrodynamic conditions can be determined from the duty parameter $\left(S_{r i}\right)$ following the proposal of Stanley et al. [35], who stated that there is a linear correlation between the $\operatorname{Ln}\left(f_{r i}(\alpha)\right)$ and $\operatorname{Ln}\left(S_{r i}(\alpha)\right)$ in the hydrodynamic region $\left(S_{r i}>S_{c r}\right)$; thus, known the duty parameter, $f_{r i}$ is instantaneously determined as:

$$
\operatorname{Ln}\left(f_{r i}(\alpha)\right)=m \operatorname{Ln}\left(S_{r i}(\alpha)\right)+\operatorname{Ln}(B)
$$

where $m$ and $\operatorname{Ln}(B)$ are the slope and $y$ intercepts, whose values depends on the rings geometry. In this work, the mean value of those proposed in [35] were used, thus $m=0.625$ and $\operatorname{Ln}(B)=1.962$.

In the case of operating in the mixed region $\left(S_{0}<S_{r i}<S_{c r}\right), f_{r i}(\alpha)$ is determined following the proposal of Taraza and Henein [10]:

$$
f_{r i}(\alpha)=f_{0}\left(1-\frac{\left|S_{r i}(\alpha)\right|}{S_{c r}}\right)+f_{c r}\left(\frac{\left|S_{r i}(\alpha)\right|}{S_{c r}}\right)
$$

where $S_{c r}=1 \times 10^{-4}$ is the critical duty parameter, $f_{c r}=0.0225$ is the friction coefficient when $S_{r i}=S_{c r}$, and $f_{0}=0.14$ is the dry friction coefficient. Note that for very low values of $S_{r i}, f_{r i} \approx f_{0}$, which means that the lubrication 
is in the boundary regime.

In the case of the skirt, there is always an oil film between skirt and liner due to the high contact surface; therefore, hydrodynamic regime is assumed. The instantaneous duty parameter of the $\operatorname{skirt}\left(S_{s}(\alpha)\right)$ is determined as [35, 10]:

$$
S_{s}(\alpha)=\frac{\mu v_{y, B}(\alpha)}{p_{c, s}(\alpha) L_{s}}
$$

being $L_{s}$ the skirt length and $p_{c, s}(\alpha)$ the contact pressure applied on the skirt, which is estimated from the normal force in the skirt $\left(F_{N, s}\right)$ as:

$$
p_{c, s}(\alpha)=\frac{F_{N, s}(\alpha)}{\pi D L_{s}}
$$

The friction coefficient between skirt and liner is then determined as proposed in [10]:

$$
f_{s}(\alpha)=2.5 \sqrt{S_{s}(\alpha)}
$$

Once the friction coefficient of each element of piston pack is determined, the friction force of each ring $\left(F_{f r, r i}\right)$ and the skirt $\left(F_{f r, s}\right)$ is calculated as:

$$
\begin{gathered}
F_{f r, r i}(\alpha)=f_{r i}(\alpha) F_{N, r i}(\alpha) \\
F_{f r, s}(\alpha)=f_{s}(\alpha) F_{N, s}(\alpha)
\end{gathered}
$$

and the total power lost by friction in the piston pack during one cycle $\left(N_{f r, p i s}\right)$ is determined as:

$$
N_{f r, p i s}=\sum_{r i=1}^{3}\left[\oint F_{f r, r i}(\alpha) v_{y, B}(\alpha) \mathrm{d} \alpha\right]+\oint F_{f r, s}(\alpha) v_{y, B}(\alpha) \mathrm{d} \alpha
$$

\subsection{Bearings friction losses}

The friction in the bearings accounts for $20-40 \%$ of friction losses [29]. The model presented in this work is based on the mobility method [38], in which the minimum oil film thickness $\left(h_{0}\right)$ and the journal centre location and trajectory inside the bearing are calculated. In Figure 5, the geometry of a loaded bearing is presented, where $e$ is the eccentricity between the journal and bearing centres, $v_{o}$ is the journal centre speed, $F_{\text {bear }}$ is the instantaneous load, $\varphi$ the angle between $F_{\text {bear }}$ and the centres line (attitude angle) and $\psi$ is the angle between $F_{\text {bear }}$ and $v_{o}$.

Note that $F_{\text {bear }}$ depends on the bearing location on the engine mechanism (i.e. connecting rod or crankshaft). Figure 6 presents the forces exerted on each bearing in a 4-cylinder engine. In each $i$-cylinder, the load applied on a connecting rod bearing $\left(F_{A, i}\right)$ can be directly obtained from the dynamic analysis of the engine mechanism [36]. On the other hand, despite the force exerted by each $i$-cylinder in the crankshaft $\left(F_{O, i}\right)$ can be also determined from the 
dynamic analysis of the engine mechanism, how this force is supported by each crankshaft bearing requires specific measurements or finite element analysis. According to the results shown in [39], it is accurate to assume that each of them supports half of the force of adjacent cylinders, as shown in Figure 6.

According to [38], the friction force in the bearings $\left(F_{f r, \text { bear }}\right)$ can be determined as:

$$
F_{f r, \text { bear }}=\frac{\mu D_{\text {bear }}^{2} \omega L_{\text {bear }} J_{1}^{00}}{4 c}+\frac{c \epsilon F_{\text {bear }}}{D_{\text {bear }}} \sin \varphi+\frac{2 v_{o} F_{\text {bear }}}{D_{\text {bear }} \omega} \sin \psi
$$

where $\omega$ is the angular speed assumed to be the same for the journal and bearing, $D_{\text {bear }}$ is the bearing diameter, $L_{\text {bear }}$ is the bearing length, $\mu$ is the oil dynamic viscosity, $c$ is the clearance between journal and bearing, $\epsilon=e / c$ is the eccentricity ratio, $v_{o}$ is the speed of the bearing centre displacement and $J_{1}^{00}$ is a parameter that characterize the film extent and film thickness change along the bearing, which is determined for a complete film extent as proposed by Taylor [38]:

$$
J_{1}^{00}=\int_{\theta=0}^{\theta=2 \pi} \frac{1}{1+\epsilon \cos \theta} \mathrm{d} \theta=\frac{2 \pi}{\sqrt{1-\epsilon^{2}}}
$$

The terms of the friction force in Equation (18) correspond, from left to right, to the shear stress, the pressure constituent and the translatory constituent, this last related with the movement of the journal centre [38]. The model presented in this work is a quasi-steady model; therefore, equilibrium values of $F_{\text {bear }}, e$ and $\varphi$ are reached at each crank angle, and hence, there is no translatory component $\left(v_{o}=0\right)$ [10]. Taking this into account and replacing Equation (19) in (18), $F_{f r, \text { bear }}$ can be finally calculated as:

$$
F_{\text {fr,bear }}=\frac{2 \pi \mu D_{\text {bear }}^{2} \omega L_{\text {bear }}}{c \sqrt{1-\epsilon^{2}}}+\frac{c \epsilon F_{\text {bear }}}{D_{\text {bear }}} \sin \varphi
$$

For a constant loaded bearing, the friction force correspond to the Ocvirk's short bearing theory [40]. According to this theory, $\epsilon$ can be determined as:

$$
\frac{2 F_{\text {bear }} / L_{\text {bear }}}{\omega \mu D_{\text {bear }}}\left(\frac{2 c}{D_{\text {bear }}}\right)^{2}\left(\frac{D_{\text {bear }}}{L_{\text {bear }}}\right)^{2}=\frac{\pi \epsilon}{\left(1-\epsilon^{2}\right)^{2}} \sqrt{0.62 \epsilon^{2}+1}
$$

and $\varphi$ as:

$$
\varphi=\tan ^{-1}\left[\frac{\pi \sqrt{1-\epsilon^{2}}}{4 \epsilon}\right]
$$

To solve the Equations (21) and (22), it is necessary to know specific bearing geometry. As this geometrical information is not usually available, in Table 4, typical geometrical values of engine bearings as function of engine bore are provided. 
Once the friction components presented in Equation (20) are determined, the power lost by friction in the bearings during one cycle can be calculated as:

$$
N_{\text {fr,bear }}=\sum_{i=1}^{N B}\left[\oint \frac{\omega D_{\text {bear }, i}}{2} F_{f r, b e a r, i}(\alpha) \mathrm{d} \alpha\right]
$$

where $i$ is the analysed bearing and $N B$ is the total number of bearings considered.

\subsection{Valve train friction losses}

The friction losses in valve train mechanisms depend on their design but commonly ranges between 7 and $30 \%$ of friction losses [29]; in a conventional Diesel engine with tappet follower, the rocker arm bearing accounts for about $10 \%$ of the total friction in the valve train system, the cam bearing between 1 and $12 \%$, the stem and valve guide about $2 \%$ and the cam/tappet contact between 85 and 90\% [41]. As most of the friction occurs in the cam/tappet contact, in some designs the sliding contact is replaced by a rolling contact by using a roller instead of a tappet, thus reducing the friction about $50 \%$ [42].

In this work, several models for tappet and rolling contacts are presented to provide a suitable analysis tool for most widespread valve train systems. The kinematics and dynamics of both, tappet and rolling contacts, are presented in Appendix A.

The cam and follower contact surface is separated by a thin oil film, which is exposed to very high load. This causes an elastic deformation in the cam and the follower that is comparable with the oil film thickness. To estimate the oil film thickness, the elastohydrodynamic lubrication theory can be used [43]. Therefore, the non-dimensional film thickness $(H)$ is estimated through the Dowson and Higginson proposal for line contact between two cylinders [44]:

$$
H=\frac{h_{0}}{R_{c}}=2.65 U^{0.7} G^{0.54} W^{-0.13}
$$

where $h_{0}$ is the minimum oil film thickness, key parameter to calculate the friction in the valve train, $R_{c}$ is the equivalent radius of curvature (see Appendix A) and $U, G$ and $W$ are dimensionless parameters defined as:

$$
\begin{aligned}
U & =\frac{\mu v_{e}}{E_{c} R_{c}} \\
G & =\alpha_{c} E_{c} \\
W & =\frac{F_{N, v a l v}}{E_{c} R_{c} L_{c a m}}
\end{aligned}
$$

being $v_{e}$ the entrainment velocity, $F_{N, v a l v}$ the force normal to the common tangent, $\alpha_{c}$ the pressure viscosity coefficient, $L_{c a m}$ the cam width and $E_{c}$ the effective elastic modulus calculated as [45]: 


$$
\frac{1}{E_{c}}=0.5\left[\frac{1-v_{c a m}^{2}}{E_{c a m}}+\frac{1-v_{f o l}^{2}}{E_{f o l}}\right]
$$

where $E_{c a m}$ and $E_{f o l}$ are the Young's modulus and $v_{c a m}$ and $v_{f o l}$ are the Poisson's ratios of the cam and follower respectively. As this information is not usually available, a reasonable assumption is to use the Young's modulus of the steel as the effective elastic modulus $\left(E_{c}=E_{\text {steel }}\right)$.

The friction in the cam/follower contact $\left(F_{f r, v a l v}\right)$ has two components, the boundary friction $\left(F_{b, v a l v}\right)$ due to the asperity contact, and the viscous friction component $\left(F_{v, v a l v}\right)$ due to the shear of lubricant $[45,46]$ :

$$
F_{f r, v a l v}=F_{b, v a l v}+F_{v, \text { valv }}
$$

$F_{b, v a l v}$ is determined as proposed in [47]:

$$
F_{b, v a l v}=\tau_{0} A_{a}+k_{m} P_{a}
$$

where $\tau_{0}$ is the Eyring shear stress, $A_{a}$ is the asperity area, $k_{m}$ is the pressure coefficient of the boundary shear strength and $P_{a}$ is the load carried by the asperities. The asperity area is calculated as [47]:

$$
A_{a}=\pi^{2}(\varrho \zeta \sigma)^{2} A F_{2}
$$

and $P_{a}$ can be determined as:

$$
P_{a}=\frac{16 \sqrt{2}}{15} \pi(\varrho \zeta \sigma)^{2} \sqrt{\frac{\sigma}{\zeta}} E_{c} A F_{5 / 2}
$$

being $\varrho$ the asperity density, $\zeta$ the asperities radius of curvature, $\sigma$ the composite surface roughness parameter and $A$ the Hertzian contact area that can be calculated by modelling the cam/follower contact as in the case of two cylinders [46]. In Figure 7, the typical load distribution in the cam/follower contact is presented. Thus, the Hertzian area is:

$$
A=2 b L_{c a m}
$$

being $b$ the half Hertzian width calculated as [43]:

$$
b=\sqrt{\frac{8 F_{N, v a l v} R_{c}}{\pi E_{c}}}
$$

The statistical functions $F_{2}$ and $F_{5 / 2}$ (see Equations (31) and (32)) are defined as function of the separation parameter $\left(\lambda=\frac{h_{0}}{\sigma}\right)$ as follows [46, 45]:

$$
F_{n}(\lambda)=\frac{1}{\sqrt{2 \pi}} \int_{\lambda}^{\infty}(s-\lambda)^{n} e^{-s^{2} / 2} \mathrm{~d} s
$$


It is convenient to use simplified expressions to solve Equation (35); therefore, several empirical correlations are presented in Equations (36) and (37). This kind of simplification facilitates the application of the model, and similar expressions can be also found in related works [45].

$$
\begin{aligned}
F_{2} & =1.47 e^{-\lambda}+0.0117 \lambda^{3}-0.143 \lambda^{2}+0.61 \lambda-0.93 \\
F_{5 / 2} & =2.26 e^{-\lambda}+0.03 \lambda^{3}-0.31 \lambda^{2}+1.172 \lambda-1.64
\end{aligned}
$$

In a cam/tappet follower contact, the viscous friction component $\left(F_{v, v a l v}\right)$ is determined as [46]:

$$
F_{v, v a l v}=\tau\left(A-A_{a}\right)
$$

where $\tau$ is the shear stress of the oil, which is calculated depending on whether the oil has a Newtonian or nonNewtonian performance. This can be determined by comparison of the Eyring shear stress with the actual shear stress. Therefore:

$$
\begin{array}{r}
\tau=\frac{\mu_{c} v_{s}}{h_{0}} \quad ; \text { if } \tau \leq \tau_{0} \\
\tau=\tau_{0}+\kappa p_{c} \quad ; \text { if } \tau>\tau_{0}
\end{array}
$$

being $v_{s}$ the sliding velocity, $\kappa$ the rate of change of shear stress with pressure, $p_{c}$ the pressure on the oil film contact and $\mu_{c}$ the oil viscosity at the contact point. $p_{c}$ is determined as [48]:

$$
p_{c}=\frac{F_{N, v a l v}-P_{a}}{A-A_{a}}
$$

and $\mu_{c}$ as [49]:

$$
\mu_{c}=\mu e^{\left(\alpha_{c} p_{c}\right)}
$$

Note that several parameters regarding the lubricant and surface properties are required to determine the friction components. Table 5 summarises typical values of these parameters $[46,45,50]$.

Similarly as for the cam/tappet follower contact, the friction in the cam/rolling follower contact $\left(F_{f r, v a l v}\right)$ has two components, the boundary friction $\left(F_{b, v a l v}\right)$ and the viscous friction $\left(F_{v, \text { valv }}\right)[45,46]$. The boundary component is determine as for the cam/tappet follower as shown previously in Equation (30).

To determine the viscous friction component, the tribological features of a cam/rolling follower contact must be considered. Therefore, $F_{v, v a l v}$ is determined as proposed by Goksem and Hargreaves [49], which provide a simplified expression for the case of isothermal fully flooded rolling traction (i.e. not including shear heating): 


$$
F_{v, \text { val }}=\frac{4.318}{\alpha_{c}}(G U)^{0.658} W^{0.0126} R_{c}^{\prime} L_{c a m}
$$

where $G, U$ and $W$ are determined as:

$$
\begin{aligned}
U & =\frac{\mu v_{e}}{E_{c} R_{c}^{\prime}} \\
G & =\alpha_{c} E_{c} \\
W & =\frac{F_{N, v a l v}}{E_{c} R_{c}^{\prime} L_{c a m}}
\end{aligned}
$$

Taking into account the previous analysis, Equation (47) provides the final expression used to determine the total friction in the valve train $N_{f r, v a l v}$ :

$$
N_{f r, v a l v}=N_{I V}\left[\oint F_{f r, v a l v}^{i n t}(\alpha) v_{c}^{i n t}(\alpha) \mathrm{d} \alpha\right]+N_{E V}\left[\oint F_{f r, v a l v}^{e x h}(\alpha) v_{c}^{e x h}(\alpha) \mathrm{d} \alpha\right]
$$

where the index int and $e x h$ refers to intake and exhaust, $v_{c}$ is the contact speed and $N_{I V}$ and $N_{E V}$ are the total number of intake and exhaust valves respectively.

\subsection{Coolant pump energy consumption}

To pump the coolant, centrifugal pumps with straight blades are commonly used, thus the energy consumption $\left(N_{\text {cool }}\right)$ can be determined as:

$$
N_{\text {cool }}=\frac{\Delta p_{\text {cool }} \dot{V}_{\text {cool }}}{\eta_{\text {cool }}}
$$

where $\dot{V}_{\text {cool }}$ is the coolant flow rate, $\eta_{\text {cool }}$ is the pump efficiency and $\Delta p_{\text {cool }}$ is the coolant pressure drop. As these parameters are not always available, they can be determined as follows:

$$
\Delta p_{\text {cool }}=k_{1, \text { cool }} \dot{V}_{\text {cool }}^{2}
$$

being $k_{1, \text { cool }}$ a proportionality value experimentally adjusted.

Since the coolant pump is a centrifugal machine, the mass flow does not necessarily share a linear trend with the rotating speed. However, from the experimental results shown in Figure 8, it can be stated that this hypothesis is suitable. As can be seen, the pressure and flow rate intersection points fits linearly with the engine speed having a coefficient of determination $\left(R^{2}\right)$ close to 1 . Therefore, it is reasonable to assume that:

$$
\dot{V}_{\text {cool }}=k_{2, \text { cool }} n
$$


where $k_{2, \text { cool }}$ is the proportionality constant between coolant flow and engine speed.

By combining Equations (48), (49) and (50), the following expression for $N_{\text {cool }}$ can be obtained:

$$
N_{\text {cool }}=\frac{k_{1, \text { cool }} \dot{V}_{\text {cool }}^{3}}{\eta_{\text {cool }}}=\frac{k_{1, \text { cool }} k_{2, \text { cool }}^{3} n^{3}}{\eta_{\text {cool }}}
$$

\subsection{Oil pump energy consumption}

In RICEs, the oil is usually pumped by means of gear or lobe pumps. Therefore, the power consumption $\left(N_{\text {oil }}\right)$ can be calculated as:

$$
N_{o i l}=\frac{\Delta p_{o i l} \dot{V}_{\text {oil }}}{\eta_{\text {oil }}}
$$

where $\eta_{o i l}$ is the pump efficiency, $\Delta p_{\text {oil }}$ is the oil pressure drop and $\dot{V}_{\text {oil }}$ is the coolant flow rate. In the case that $\Delta p_{\text {oil }}$ and $\dot{V}_{\text {oil }}$ are not available from measurements, they must be estimated. On the one hand, taking into account that the oil pump is a volumetric machine, the oil flow rate can be obtained as a function of the engine speed as:

$$
\dot{V}_{\text {oil }}=k_{1, \text { oil }} n
$$

where $k_{1, \text { oil }}$ is the proportionality between oil flow and engine speed.

On the other hand, since the pump has a relief valve, $\Delta p_{o i l}$ depends on $\dot{V}_{\text {oil }}$ until a certain engine speed $\left(n_{\Delta p, \max }\right)$ at which the maximum oil pressure $\left(\Delta p_{\text {oil,max }}\right)$ is reached. For values lower than $\Delta p_{\text {oil,max }}\left(n<n_{\Delta p, \max }\right), \Delta p_{\text {oil }}$ can be determined by considering a simplified model in which the pressure losses in a pipe is computed.

The friction factor in a pipe $\left(f_{\text {pipe }}\right)$ can be obtained with the Darcy-Weisbach equation:

$$
\begin{aligned}
\Delta p_{\text {oil }} & =\frac{8 f_{\text {pipe }} L_{\text {pipe }}}{\pi^{2} D_{\text {pipe }}^{2} g} \dot{V}_{\text {oil }}^{2} \\
& =k_{2, \text { oil }}^{\prime} f_{\text {pipe }} \dot{V}_{\text {oil }}^{2}
\end{aligned}
$$

being $L_{\text {pipe }}$ the pipe length, $D_{\text {pipe }}$ the pipe diameter, $g$ the gravity and $k_{2, \text { oil }}^{\prime}=8 L_{\text {pipe }} / \pi^{2} D_{\text {pipe }}^{2} g$ a constant value. To determine $f_{\text {pipe }}$, the empirical formula of Moody can be used [51]:

$$
f_{\text {pipe }}=0.001375\left\{1+\left[200 \sigma_{r}+\frac{\pi D_{\text {pipe }} \mu_{\text {oil }} \times 10^{6}}{4 \dot{V} \rho_{\text {oil }}}\right]^{1 / 3}\right\}
$$

where $\sigma_{r}$ is the pipe rugosity, $\mu_{o i l}$ is the oil dynamic viscosity and $\rho_{\text {oil }}$ is the oil density. 
In practice, it is not easy to choose representative values for $\sigma_{r}$ and $D_{\text {pipe }}$ to solve Equation (55), thus, a simpler proposal based on this expression is presented:

$$
f_{\text {pipe }}=\left(\frac{k_{3, \text { oil }}^{\prime} \mu_{\text {oil }}}{\dot{V}_{\text {oil }}}\right)^{k_{3, \text { oil }}}
$$

Replacing Equation (56) into (54), and bearing in mind that $\dot{V}_{\text {oil }}=k_{1, \text { oil }} n$, the following expression for $\Delta p_{\text {oil }}$ is obtained:

$$
\Delta p_{\text {oil }}=k_{2, \text { oil }}^{\prime}\left(\frac{k_{3, \text { oil }}^{\prime} \mu_{\text {oil }}}{\dot{V}_{\text {oil }}}\right)^{k_{3, \text { oil }}} \dot{V}_{\text {oil }}^{2}=\left(\frac{k_{2, \text { oil }} \mu_{\text {oil }}}{k_{1, \text { oil }} n}\right)^{k_{3, \text { oil }}}\left(k_{1, \text { oil }} n\right)^{2}
$$

Note that, if the oil pressure is measured at some point along the oil line, it can be used either directly in Equation (52) or to calibrate the constants $k_{2, \text { oil }}$ and $k_{3, \text { oil }}$ of Equation (57). Regardless of whether this information is available, the set of equations presented in this section allows modelling the oil pump power consumption. Therefore, from Equation (52) and taking into account Equations (53) and (57), the oil pump power can be determined as:

$$
\begin{array}{r}
N_{\text {oil }}=\frac{k_{1, \text { oil }} n \Delta p_{\text {oil,max }}}{\eta_{\text {oil }}} \text {; if } \Delta p_{\text {oil }}=\Delta p_{\text {oil,max }} \\
N_{\text {oil }}=\frac{\left(k_{1, \text { oil }} n\right)^{3}}{\eta_{\text {oil }}}\left(\frac{k_{2, \text { oil }} \mu_{\text {oil }}}{k_{1, \text { oil }} n}\right)^{k_{3, \text { oil }}} \text {; if } \Delta p_{\text {oil }}<\Delta p_{\text {oil,max }}
\end{array}
$$

\subsection{Fuel pump consumption}

In conventional piston pumps, the total amount of fuel compressed by the pistons (part of which is injected and part returns to the low pressure circuit) depends on the pump rotating speed and pump size, thus the volumetric flow $\left(\dot{V}_{f}\right)$ is proportional to the engine speed. Thereby, the fuel pump power depends on the engine speed and the pressure drop $\left(\Delta p_{f}\right)$, which can be assumed to be equal to the rail pressure $\left(p_{\text {rail }}\right)$, taking into account that $p_{\text {rail }}$ is much higher than the feeding pressure. Taking into account these comments, Equations (60) and (61) are proposed:

$$
\begin{aligned}
N_{f} & =\frac{\dot{V}_{f} \Delta p_{f}}{\eta_{f}} \\
& =\frac{k_{1, f}^{\prime} n p_{\text {rail }}}{\eta_{f}}
\end{aligned}
$$

where $k_{f}^{\prime}$ is the proportionality constant between $\dot{V}_{f}$ and $n$, and $\eta_{f}$ is the pump efficiency.

It is important to consider that, some new fuel pumps include both, a pressure control valve and a volume control valve, which performance differs from conventional piston pumps. As can be seen in Figure 9 (a), the fuel pump power consumption $\left(N_{f}\right)$ in this kind of pumps depends on $p_{\text {rail }}, n$ and the injected fuel mass as well. To determine the power consumption, a characterization campaign was carried out through a modification of the engine and the 
test bench, consisting on dismounting the injectors from the combustion chambers and performing motoring tests at different speed, $p_{\text {rail }}$ and injected fuel mass (injecting in a vessel). The rest of friction losses were kept constant by controlling the oil temperature, thus the mechanical losses variations can be only attributed to injection setting changes.

Firstly, a motoring test without fuel pump activation $\left(p_{\text {rail }}=0\right)$ is measured to determine the reference power consumption of the engine $\left(N_{f, 0}\right)$. Then, $p_{\text {rail }}$ and the injected fuel mass were swept. The power required to drive the fuel pump is then calculated as the difference between the current power consumption and the reference power as presented in Equation (62):

$$
N_{f}=2 \pi n M_{e}-N_{f, 0}=\frac{\Delta p_{f} \dot{V}_{f}}{\eta_{f}}
$$

where $M_{e}$ is the brake torque.

In Figure 9 (b), the variation of $M_{e}$ due to the injection of a high $\left(m_{f}+\right)$ or a low $\left(m_{f}-\right)$ fuel amount is presented. This dependency with $m_{f}$ is explained by the strategy of the ECU, which manages the volume control valve and regulates the amount of fuel compressed in the high pressure pump to reduce the power waste.

Due to the difficulty to determine $\dot{V}_{\text {fuel }}$ in this kind of pumps, an empirical correlation was adjusted based on the experimental results:

$$
\dot{V}_{f}=k_{1, f} \dot{m}_{f}^{k_{2, f}}
$$

where $k_{1, f}$ and $k_{2, f}$ are calibration constants and $\dot{m}_{f}$ is the total fuel mass injected.

Finally, by replacing Equation (63) in (60), the power consumption can be estimated as:

$$
N_{f}=\frac{k_{1, f} \dot{m}_{f}^{k_{2, f}} p_{\text {rail }}}{\eta_{f}}
$$

In Figure 10, the comparison between the experimental and modelled fuel pump power is presented. It is possible to see how the model fits well in all operating conditions measured, considering a wide engine speed, $p_{\text {rail }}$ and fuel mass range.

\section{Model calibration and validation}

To adjust the mechanical losses model, the total modelled losses $\left(\left(N_{f r}+N_{a}\right)_{m o d}\right)$ are compared with the experimental ones $\left(\left(N_{f r}+N_{a}\right)_{\text {exp }}\right)$. Thus, the adjustment criterion is the reduction of the difference between them: 


$$
\begin{aligned}
\left(N_{f r}+N_{a}\right)_{\text {exp }} & =\left(N_{f r}+N_{a}\right)_{\text {mod }} \\
& =k_{\text {pis }} N_{f r, p i s}+k_{\text {bear }} N_{f r, \text { bear }}+k_{\text {valv }} N_{f r, \text { alv }}+k_{\text {cool }} N_{\text {cool }}+k_{\text {oil }} N_{\text {oil }}+k_{f} N_{f}
\end{aligned}
$$

As shown in Equation (65), six calibration constants have to be adjusted. In order to assure the calibration robustness, it is desirable to reduce this amount of parameters. Therefore, the auxiliary $\left(N_{c o o l}, N_{o i l}\right.$ and $\left.N_{f}\right)$ were calibrated based on information provided by manufacturers and by means of dedicated experimental campaigns. Table 6 summarizes the calibration constants obtained to determine the power of the coolant, oil and fuel pumps from Equations (51), (59) and (64) respectively.

Since the auxiliary systems were prior calibrated, the terms $k_{c o o l}, k_{o i l}$ and $k_{f}$ of Equation (65) become 1 . The adjustment of the friction constants $\left(k_{p i s}, k_{\text {bear }}\right.$ and $\left.k_{v a l v}\right)$ was performed in the engine map.

It is important to notice that the accurate estimation of friction components depends on the derivation of suitable values for the empirical coefficients. The discrepancy of the constants with respect to the reference values (i.e. $\left.k_{\text {pis }}=k_{\text {bear }}=k_{\text {valv }}=1\right)$ is a consequence of uncertainties regarding the elements geometry, load determination and sub-models imperfections. This discrepancy with respect to reference values is also reported in other works [52], which proposed "variable" constants values as a function of the engine speed. As it was found that friction losses were overestimated at low engine speed, this approach was also considered in this work. A linear correlation for the piston constant as function of the engine speed ( $n$ ) was finally proposed: $k_{p i s}=k_{1, p i s}+k_{2, p i s} n$. In the case of $k_{\text {bear }}$ and $k_{v a l v}$, no clear improvement was found by applying this approach; therefore, they were maintained constant for all operating conditions. In Table 7, the results of the friction models calibration campaign are summarized.

Figure 11 shows the mechanical losses repartition in the engine map. In the upper Figure 11, it is possible to see the good agreement between the experimental and modelled total mechanical losses, having a good behaviour for all the operating points. In the bottom of Figure 11, it is possible to see the good agreement of $N_{a}+N_{f r}$ relative distribution when compared with that found in the literature [10, 53, 54], being $N_{f r, p i s}$ between $40-60 \%, N_{f r \text {,bear }}$ between $15-25 \%, N_{f r, v a l v}$ between 5 and $15 \%, N_{\text {cool }}$ about $15 \%, N_{\text {oil }}$ about $5 \%$ and $N_{f}$ about $20 \%$ of the total $N_{a}+N_{f r}$.

\section{Results and discussion}

\subsection{Mechanical losses analysis}

Once the mechanical losses model was calibrated and validated, a brief application to determine the detailed mechanical losses in a conventional Diesel engine is presented. In this regard, the following comments can be made: 
- Friction values of piston pack, bearings and valve train throughout the engine map are shown in Figures 12, 13 and 14. In absolute terms, the friction increases mainly with the speed, except in the piston pack where it increase with both speed and load. This is explained by the fact that friction power is highly dependent on the engine speed [39], as can be seen in Equations (17), (23) and (47). In addition, the friction coefficient, used to calculate the friction force, depends mostly on the engine speed. Nevertheless, in relative terms, the friction decreases when increasing the load, which is explained by the higher input of fuel energy.

As can be seen, $N_{f r, p i s}$ is the most important friction term, reaching values up to $5.5 \% \dot{m}_{f} H_{v}$ at high speed and low load, followed by $N_{f r, b e a r}$ with a maximum weight of $2 \% \dot{m}_{f} H_{v}$ at low load and high speed, and finally, the less important term is $N_{f r, v a l v}$, whose maximum value is $0.8 \% \dot{m}_{f} H_{v}$ at low load.

- The coolant, oil and fuel pumps energy consumption is shown in Figures 15, 16 and 17. As can be seen, the absolute power of the coolant and oil pumps is proportional to the engine speed. However, their relative weight changes with both, speed and load. The relative weight of $N_{\text {cool }}$ ranges between $0.2-1 \% \dot{m}_{f} H_{v}$, being specially important at high speed and low load, whilst $N_{\text {oil }}$ maximum weight lies between $0.3-0.4 \% \dot{m}_{f} H_{v}$ at low load. The general higher weight of $N_{\text {cool }}$ is explained by the higher coolant flow requirements.

In the case of the fuel pump, its absolute power increases with both, speed and load, since this pump has a pressure control valve and a volume control valve. Therefore, the compressed fuel is controlled by the ECU at low load to reduce unnecessary fuel pumping. As a consequence, the relative weight of $N_{f}$ in the complete map is almost constant about $0.6-0.8 \% \dot{m}_{f} H_{v}$.

\subsection{Evaluation of the use of a rolling follower}

As a brief example of the possible applications of this model, an example of the expected friction reduction due to change the cam/follower system is presented. The study consist on evaluating the effect of using a rolling follower instead of the original tappet follower. To perform the study, the valve train friction model for rolling followers has to be calibrated in an engine with this system. Therefore, an engine with the same geometry and performance as the original engine, but with a rolling follower was used. In Figure 18, the calibration performance of the mechanical losses in the new engine is presented. As can be seen, there is a good agreement between the modelled and experimental results, ensuring a good behaviour of the model. As the detailed results are very similar as those obtained in the reference engine used in this work, no further analysis will be presented.

Once the model is calibrated, it can be used to assess the friction of a rolling follower in the reference engine. In Figure 19, the results of the friction in the cam/follower contact at full load by using both, tappet and rolling followers, is presented. As can be seen, a reduction of the friction about $50 \%$ at low speed and $70 \%$ at high speed can 
be expected. The results observed are consistent with those reported by other authors [42], which demonstrates the potential of the tool described in predictive applications.

\section{Conclusions}

In this work, semi-empirical sub-models to calculate the friction between piston pack and liner, bearings and valve train have been proposed, considering the kinematic, dynamic and tribological processes of each element. Similarly, simple sub-models to determine the coolant, oil and fuel pumps power have been developed, taking into account simplified geometrical information to estimate the mass flow and pressure drop of each pump. For these friction and auxiliary models, calibration constants can be adjusted based on experimental information obtained in standard test benches.

An application to evaluate friction and auxiliary losses in the complete map of a conventional Diesel engine was presented, being the most relevant observations as follows:

- Most of the engine friction takes place in the piston pack, being about $40-60 \%$ of the total mechanical losses, and reaching up to $5.5 \% \dot{m}_{f} H_{v}$ relative to the total input energy.

- Bearings friction reaches up to $2 \% \dot{m}_{f} H_{v}$, whilst the valve train friction represents less than $1 \% \dot{m}_{f} H_{v}$.

- The fuel pump has an energy consumption of about $0.7 \% \dot{m}_{f} H_{v}$, being the most important of the auxiliary energy losses. The coolant and oil pump have an energy consumption lower than $0.4 \% \dot{m}_{f} H_{v}$.

To demonstrate the predictive potential of the model, a study consisting on replace the cam/tappet follower model to a calibrated cam/rolling follower was performed. The results shows that using rolling followers can reduce the friction in the valve train up to $70 \%$. 


\begin{tabular}{ll}
\hline Feature & Description \\
\hline Cylinders & 4 in-line \\
Strokes & 4 \\
Bore $[\mathrm{mm}]$ & 75 \\
Stroke $[\mathrm{mm}]$ & 88 \\
Unitary displacement $\left[\mathrm{cm}^{3}\right]$ & 390 \\
Total displacement $\left[\mathrm{cm}^{3}\right]$ & 1560 \\
Compression ratio & $16: 1$ \\
Air management & Turbocharged \\
Maximum power $[\mathrm{kW}]$ & 82 at 3600 rpm \\
Maximum torque $[\mathrm{Nm}]$ & 270 at $1750 \mathrm{rpm}$ \\
Cycle & Diesel \\
Injection & Common rail \\
Valve train & cam/tappet contact \\
\hline
\end{tabular}

Table 1: Tested Engine technical data

\begin{tabular}{llll}
\hline Variable & Equipment & Range & Accuracy \\
\hline Cylinder pressure & AVL GH13P & 0 to $250 \mathrm{bar}$ & Linearity $0.3 \%$ \\
Amplifier & Kistler 5011B & $\pm 10 \mathrm{~V}$ & - \\
Speed control & SIEMENS Dynamometer & $6000 \mathrm{rpm}$ & $\pm 2 \mathrm{rpm}$ \\
Torque control & SIEMENS Dynamometer & $\pm 450 \mathrm{Nm}$ & $0.5 \mathrm{Nm}$ \\
Air mass flow & Sensiflow DN80 & 20 to $720 \mathrm{~kg} / \mathrm{h}$ & $2 \%$ \\
Fuel mass flow & AVL 733S Fuel meter & 0 to $150 \mathrm{~kg} / \mathrm{h}$ & $0.2 \%$ \\
Blow-by mass flow & AVL blow-by Meter & 1.5 to $75 \mathrm{l} / \mathrm{min}$ & $1.5 \%$ \\
Temperature & K-type Thermocouples & -200 to $1250{ }^{\circ} \mathrm{C}$ & $1.5^{\circ} \mathrm{C}$ \\
Mean pressure & Kistler Piezo-resistive Pressure Transmitters & $0-10 \mathrm{bar}$ & Linearity $0.2 \%$ \\
\hline
\end{tabular}

Table 2: Test cell instrumentation 


\begin{tabular}{lll}
\hline Paramenter & Range & Step \\
\hline Speed & 1000 to $4000 \mathrm{rpm}$ & $500 \mathrm{rpm}$ \\
Load & 25 to $100 \%$ & $25 \%$ \\
$T_{\text {cool }}$ & $85^{\circ} \mathrm{C}$ & - \\
$T_{\text {oil }}$ & 90 to $120^{\circ} \mathrm{C}$ & Depending on the operating point \\
\hline
\end{tabular}

Table 3: Measured operating points

\begin{tabular}{lcc}
\hline Parameter & Connecting rod & Crankshaft \\
\hline$D_{\text {bear }}$ & $0.7 \mathrm{D}$ & $0.6 \mathrm{D}$ \\
$L_{\text {bear }}$ & $0.28 \mathrm{D}$ & $0.24 \mathrm{D}$ \\
$e$ & $0.0005 \mathrm{D}$ & $0.0004 \mathrm{D}$ \\
$c$ & $0.0018 \mathrm{D}$ & $0.0015 \mathrm{D}$ \\
\hline
\end{tabular}

Table 4: Bearings geometrical parameters determination in function of cylinder bore

\begin{tabular}{lcc}
\hline Parameter & Value & Units \\
\hline$\alpha_{c}$ & $1.4 \times 10^{-8}-1.8 \times 10^{-8}$ & $\mathrm{~m}^{2} / \mathrm{N}$ \\
$\sigma$ & 0.4 & $\mu \mathrm{m}$ \\
$(\sigma / \zeta)$ & 0.001 & - \\
$(\varrho \zeta \sigma)$ & 0.055 & - \\
$\tau_{0}$ & $2-10$ & $\mathrm{MPa}$ \\
$k_{m}$ & 0.17 & - \\
$\kappa$ & 0.08 & - \\
$E_{c}$ & $187-210$ & $\mathrm{GPa}$ \\
\hline
\end{tabular}

Table 5: Typical values of the model parameters

\begin{tabular}{ll|ll|ll}
\hline \multicolumn{2}{c}{ Coolant pump } & \multicolumn{2}{c}{ Oil pump } & \multicolumn{2}{c}{ Fuel pump } \\
\hline$k_{1, \text { cool }}$ & $5.14 \times 10^{-5} \frac{\text { bar }}{(l / m i n)^{2}}$ & $k_{1, \text { oil }}$ & $7.9 \times 10^{-3} \frac{l / m i n}{r p m}$ & $k_{1, f}$ & $3.43 \times 10^{-9} \frac{\mathrm{m}^{3} / s}{(g / s)^{0.6}}$ \\
$k_{2, \text { cool }}$ & $5.51 \times 10^{-2} \frac{l / m i n}{r p m}$ & $k_{2, \text { oil }}$ & $2.03 \frac{\text { bar }}{(l / m i n)^{2}}$ & $k_{2, f}$ & 0.6 \\
& & $k_{3, \text { oil }}$ & 0.64 & & \\
\hline
\end{tabular}

Table 6: Calibration constants of the auxiliary losses models

\begin{tabular}{ccccccc}
\hline$k_{1, \text { pis }}$ & $k_{2, \text { pis }}$ & $k_{\text {bear }}$ & $k_{\text {valv }}$ & $k_{\text {cool }}$ & $k_{\text {oil }}$ & $k_{f}$ \\
\hline 0.498 & $2.28 \times 10^{-3} \mathrm{rpm}^{-1}$ & 3.9 & 2.5 & 1 & 1 & 1 \\
\hline
\end{tabular}

Table 7: Calibration constants of the friction and auxiliary losses models 


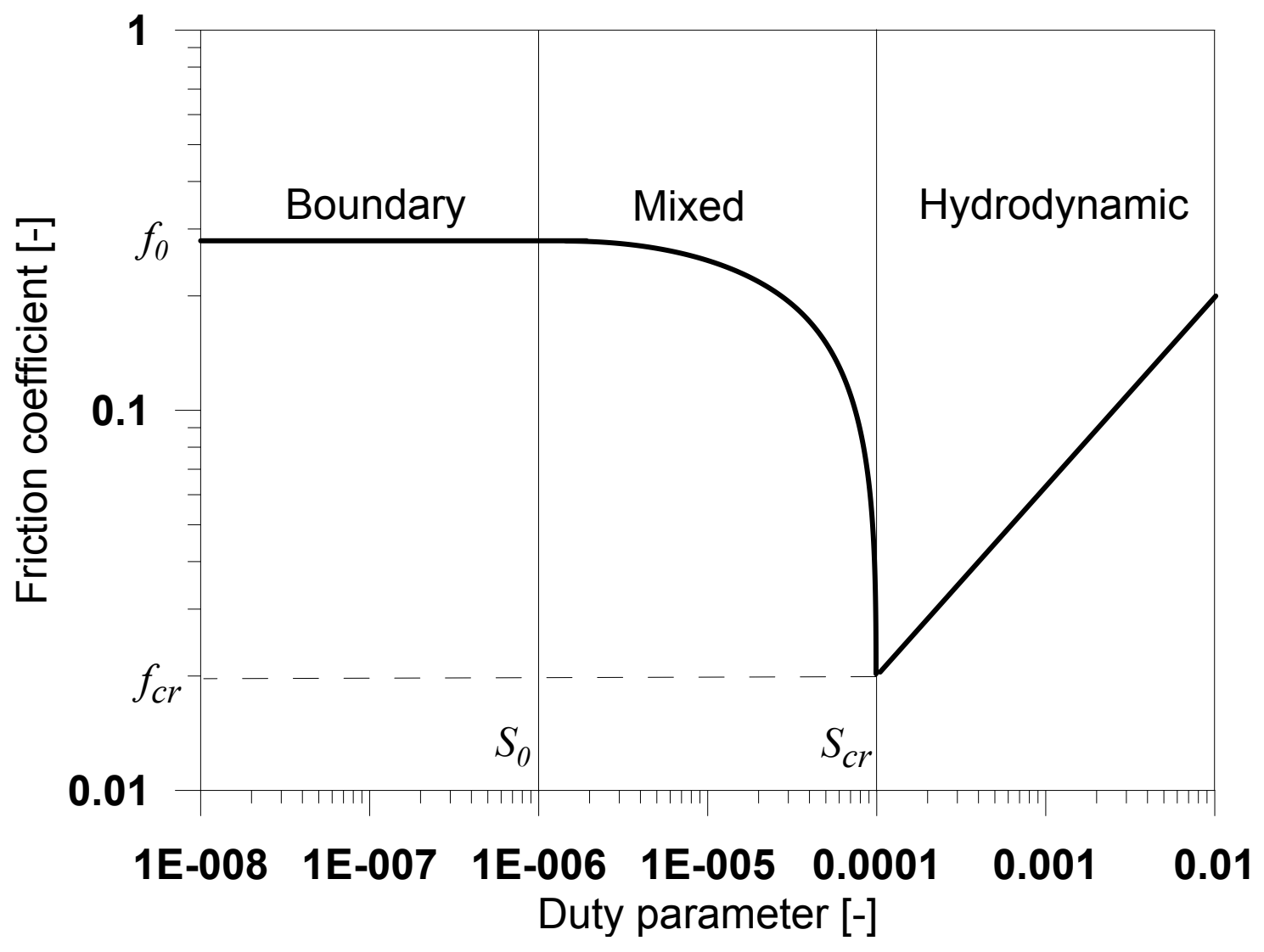

Figure 1: Stribeck diagram 


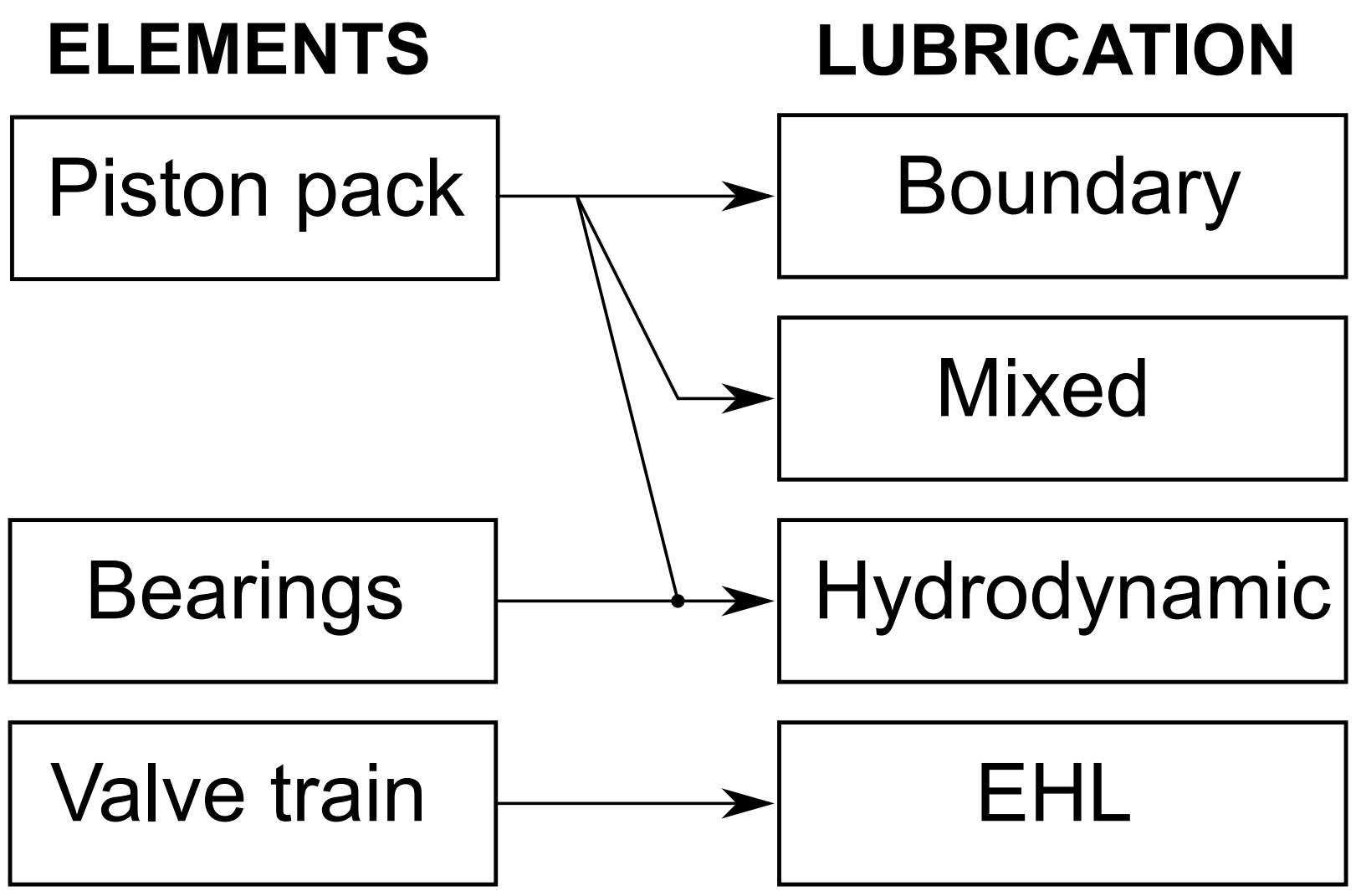

Figure 2: Lubrication regimes for each element 


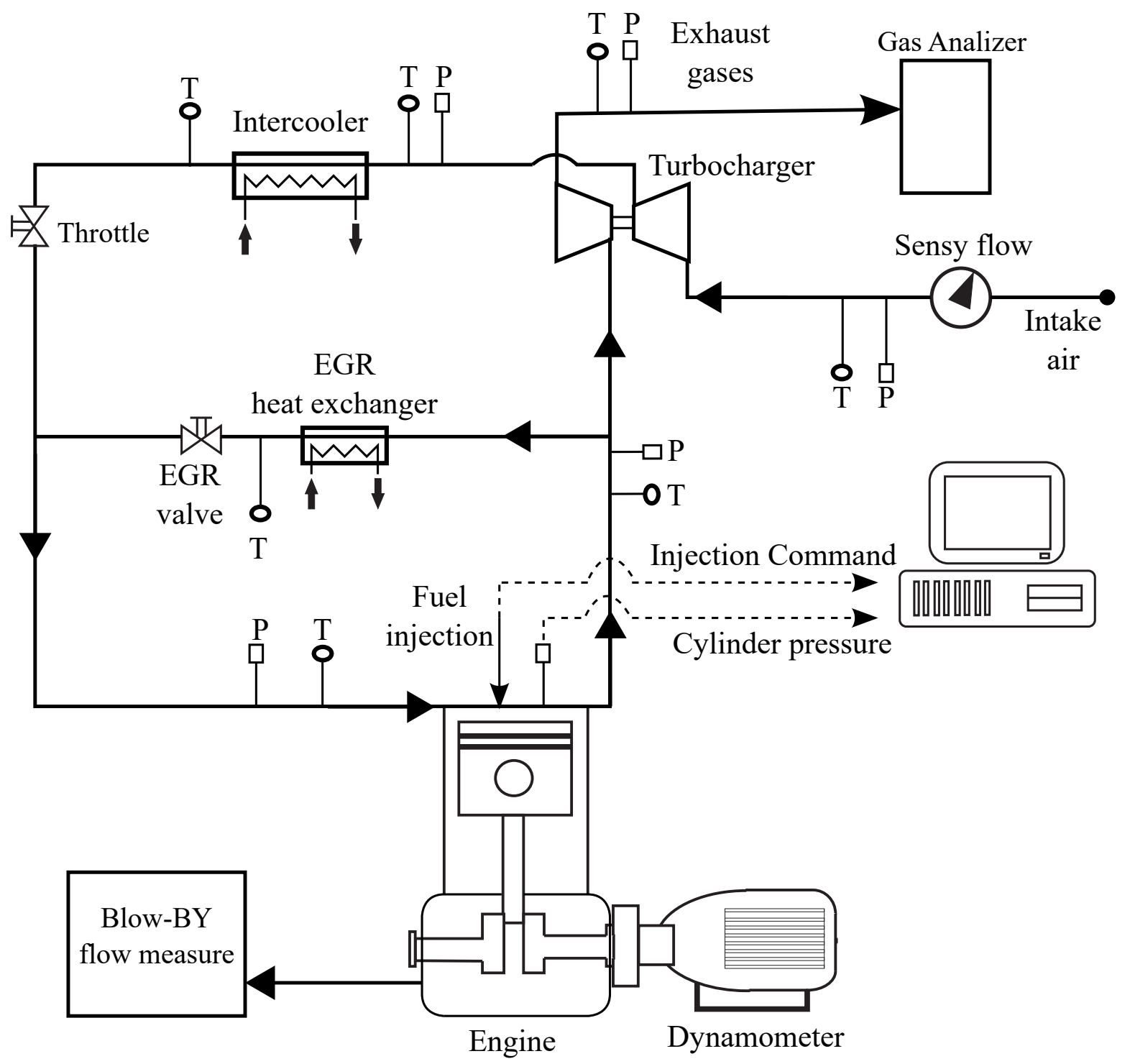

Figure 3: Scheme of the experimental facility 


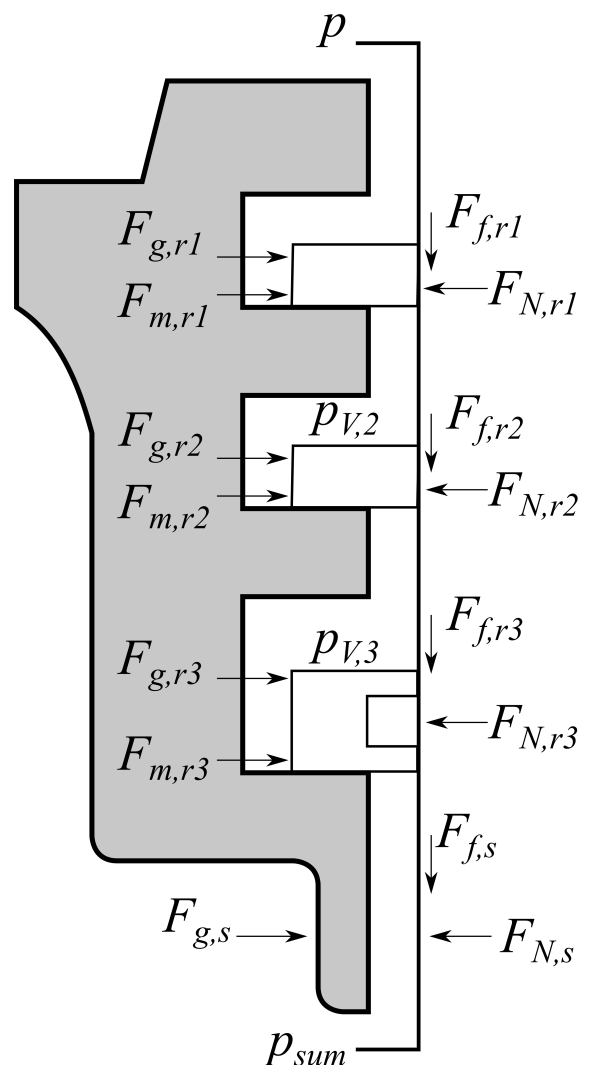

Figure 4: Forces acting on the piston pack

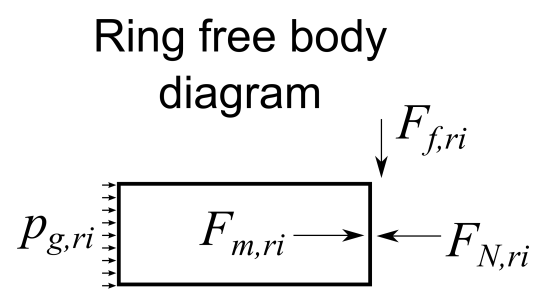

$$
\begin{gathered}
\text { Oil ring free body } \\
\text { diagram }
\end{gathered}
$$

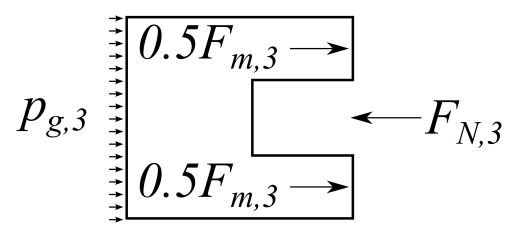




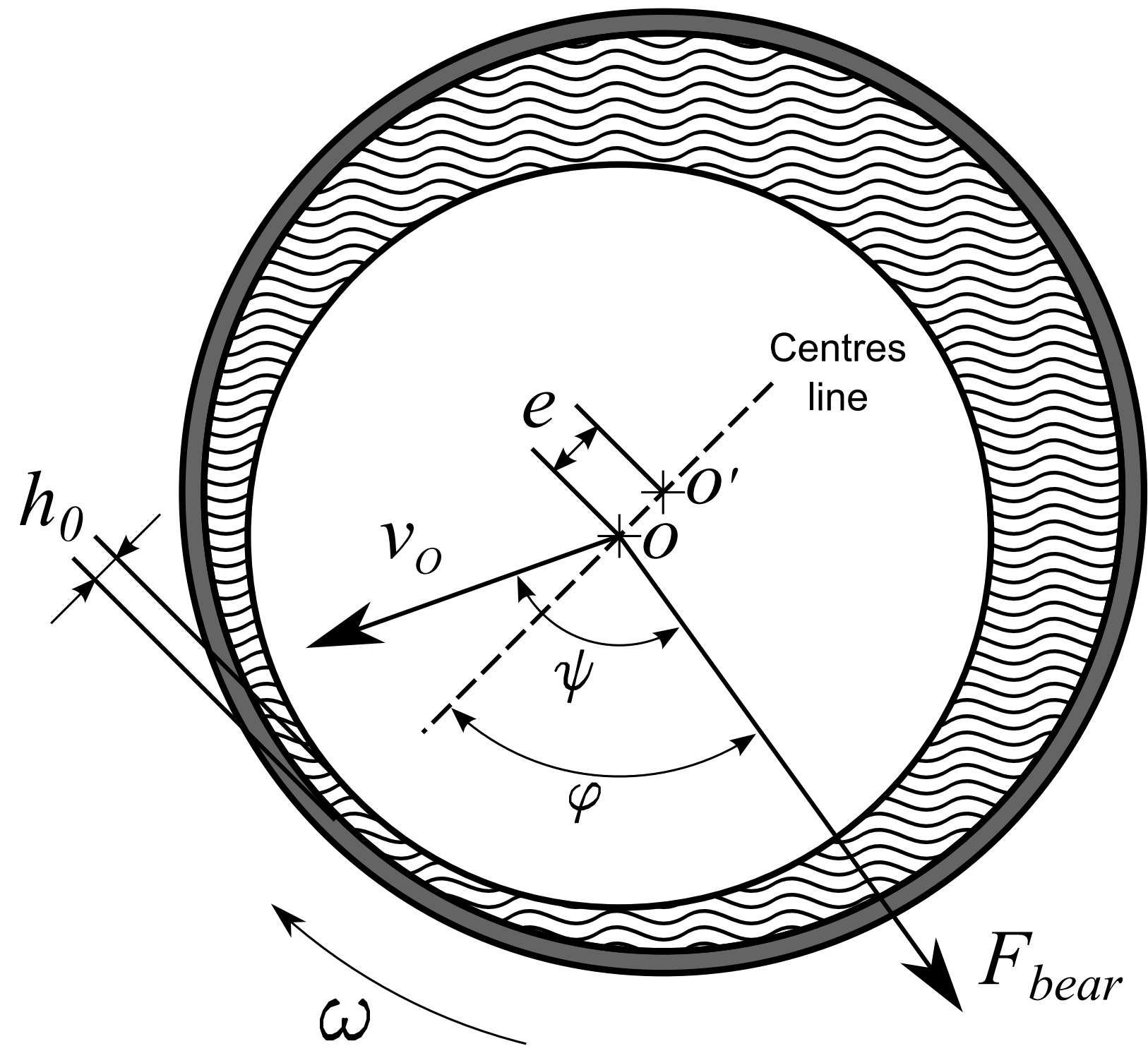

Figure 5: Scheme of bearings geometry 


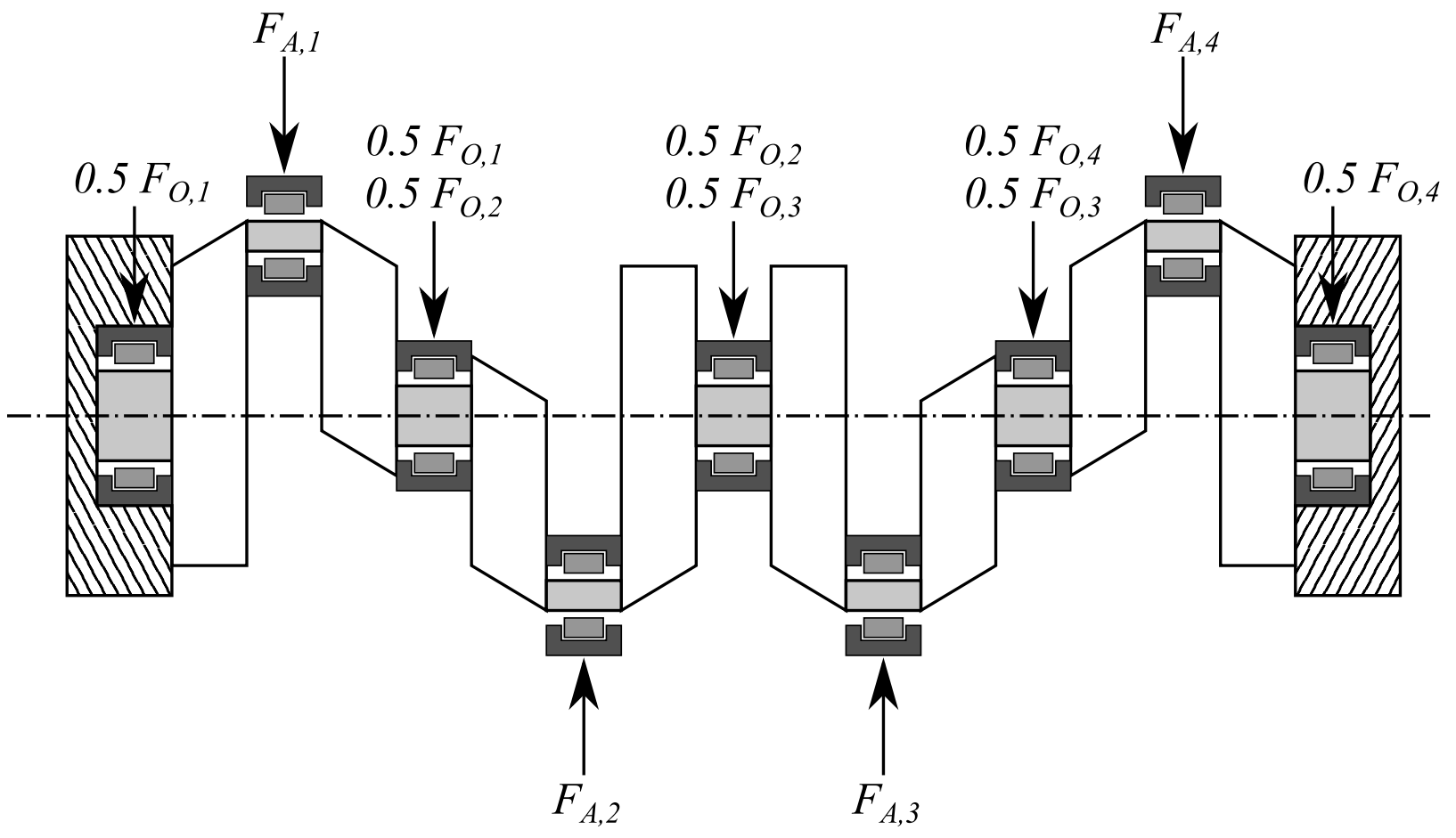

Figure 6: Scheme of loads applied on the bearings in a 4-cylinder engine

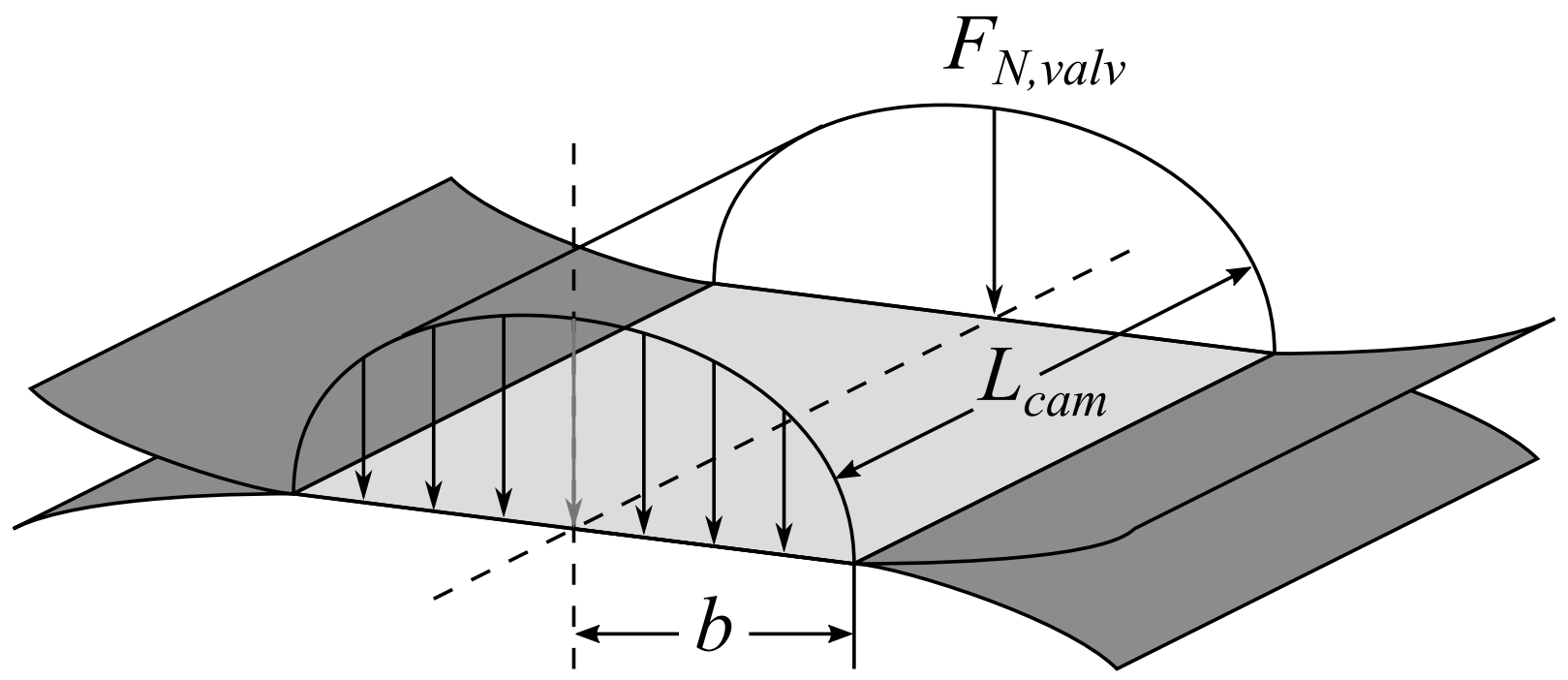

Figure 7: Hertzian contact area 

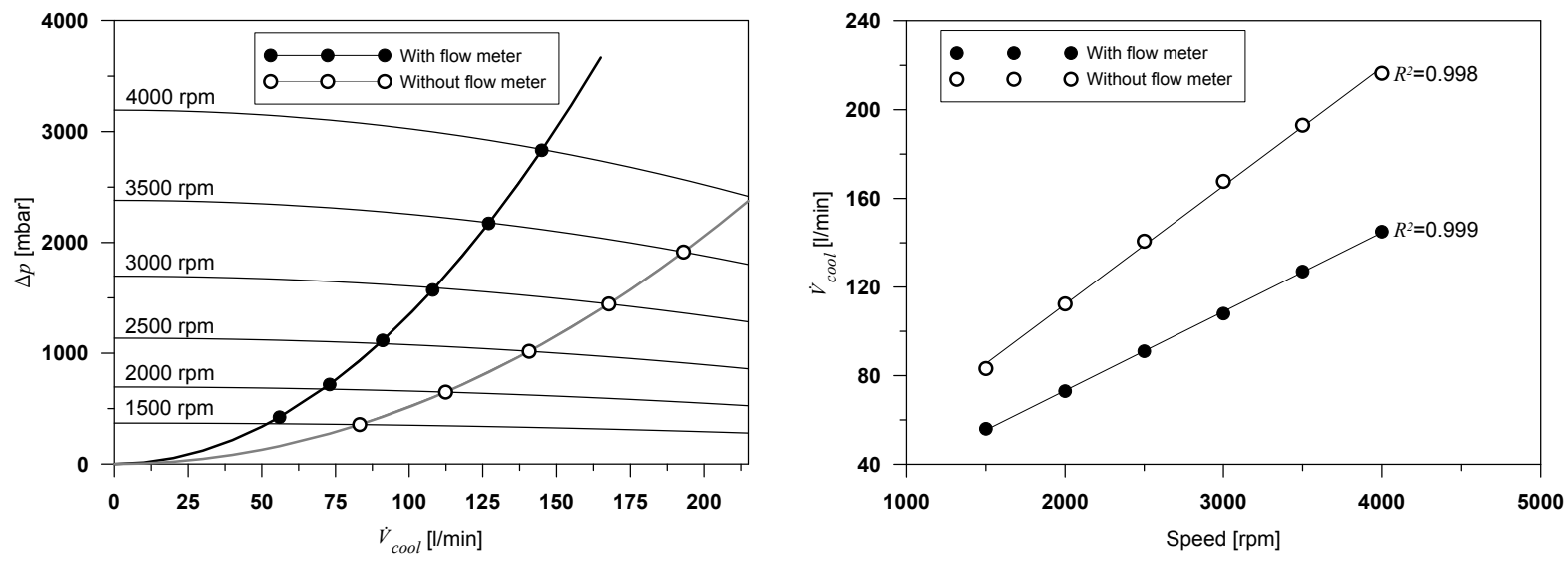

Figure 8: Pressure drop at different coolant flow and engine speed in a typical Diesel engine

(a)

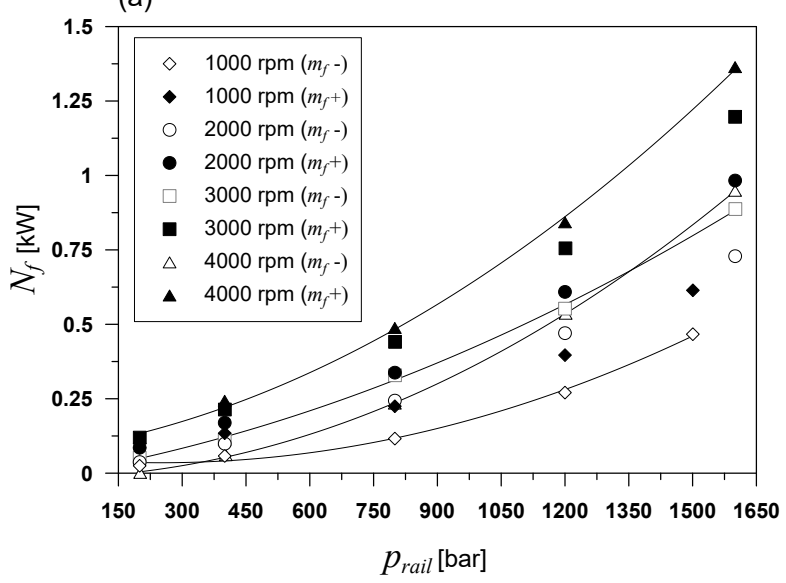

(b)

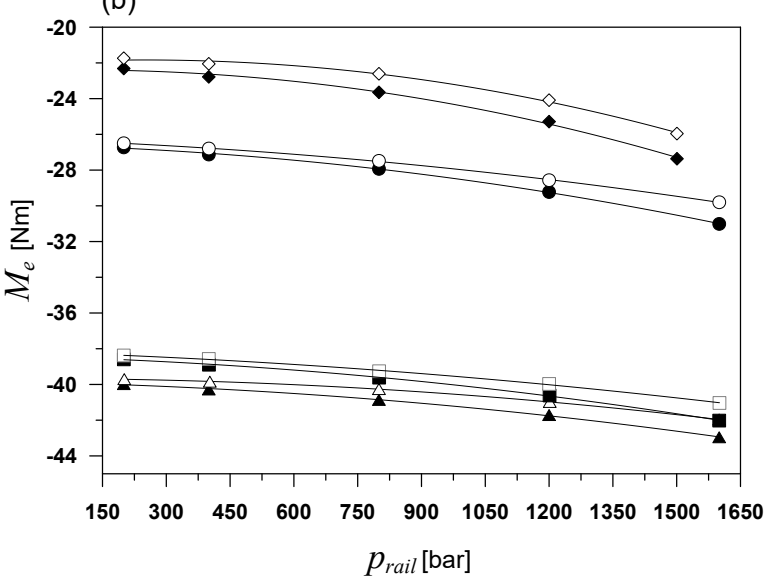

Figure 9: Fuel pump power (left) and brake torque (right) at two levels of injected fuel mass 


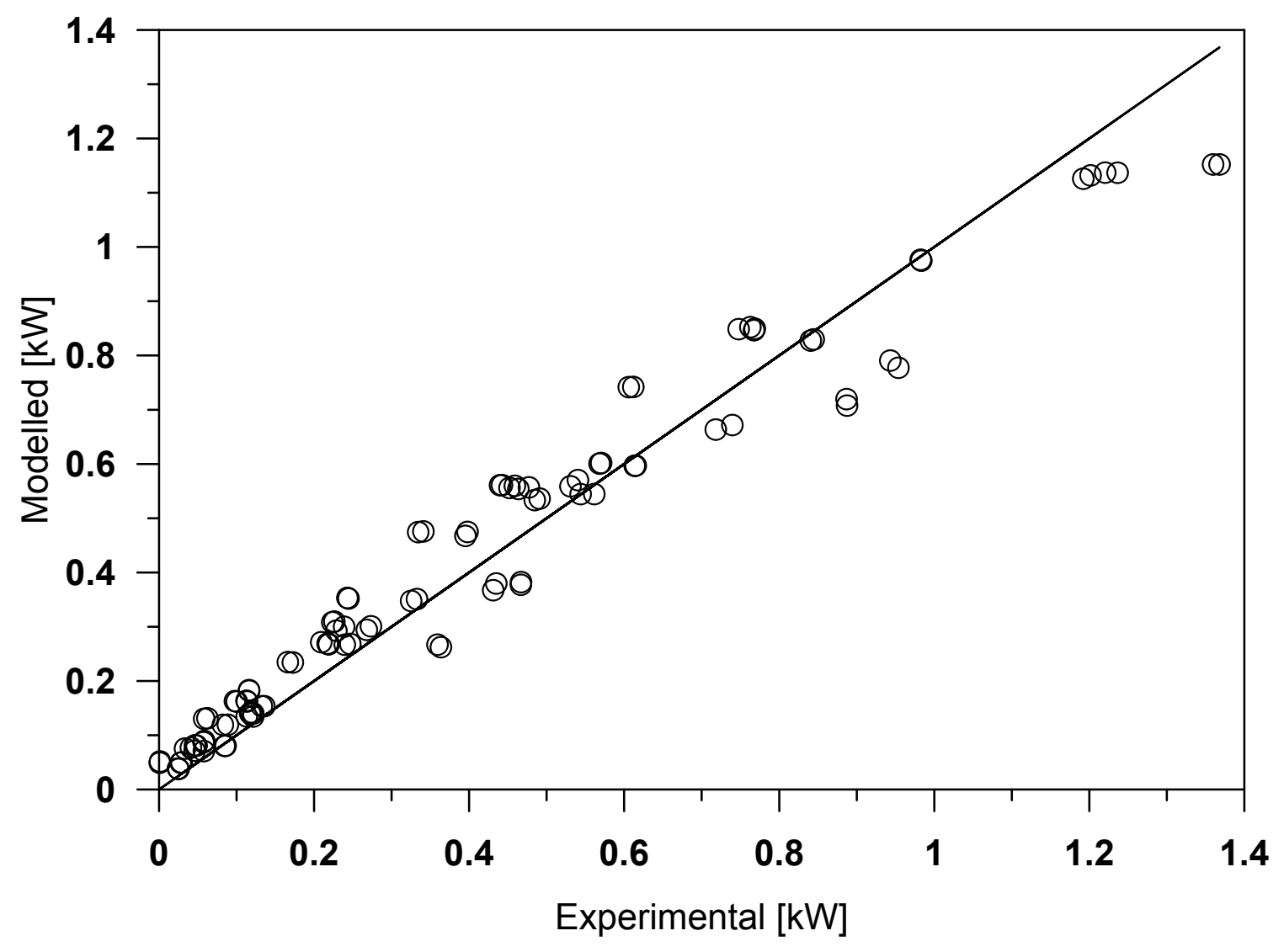

Figure 10: Experimental and modelled fuel pump power consumption 

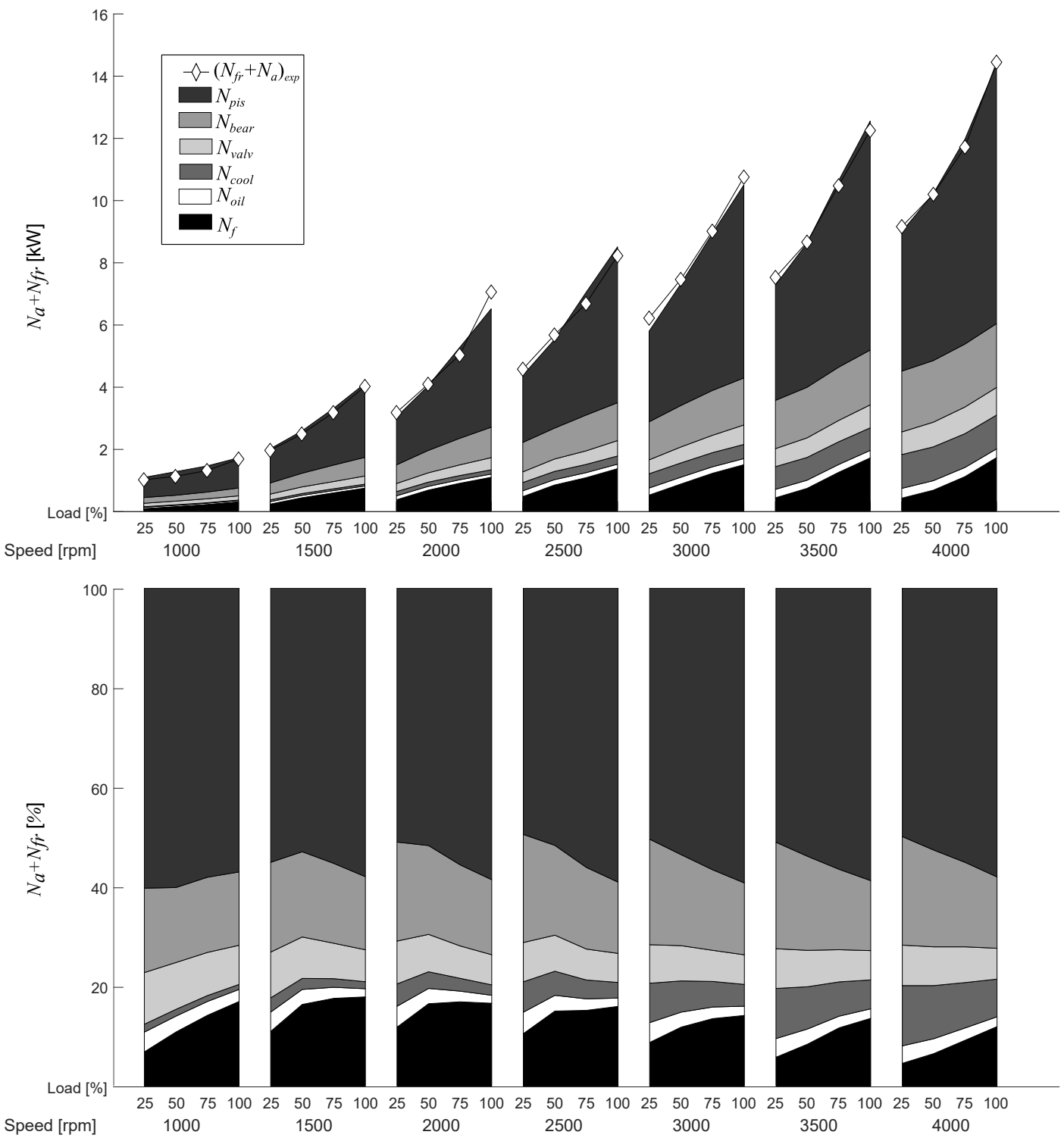

Figure 11: Auxiliary and friction results 

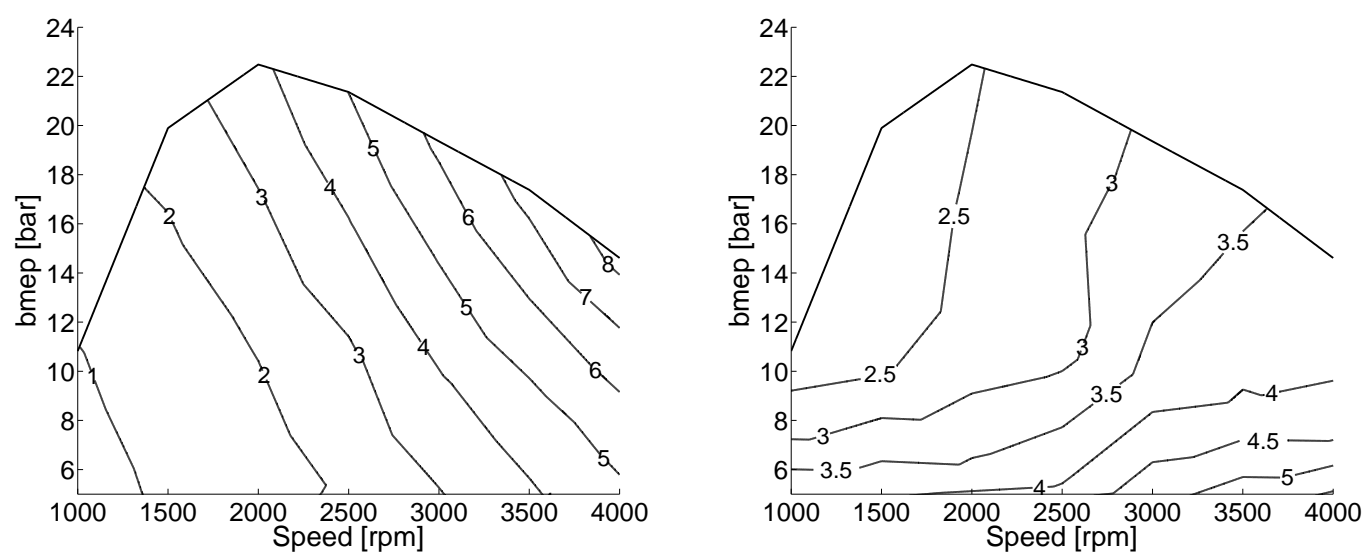

Figure 12: Friction between piston pack and liner $\left(N_{f r, p i s}\right)$. Left: absolute value $(\mathrm{kW})$. Right: relative value $\left(\% \dot{m}_{f} H_{v}\right)$
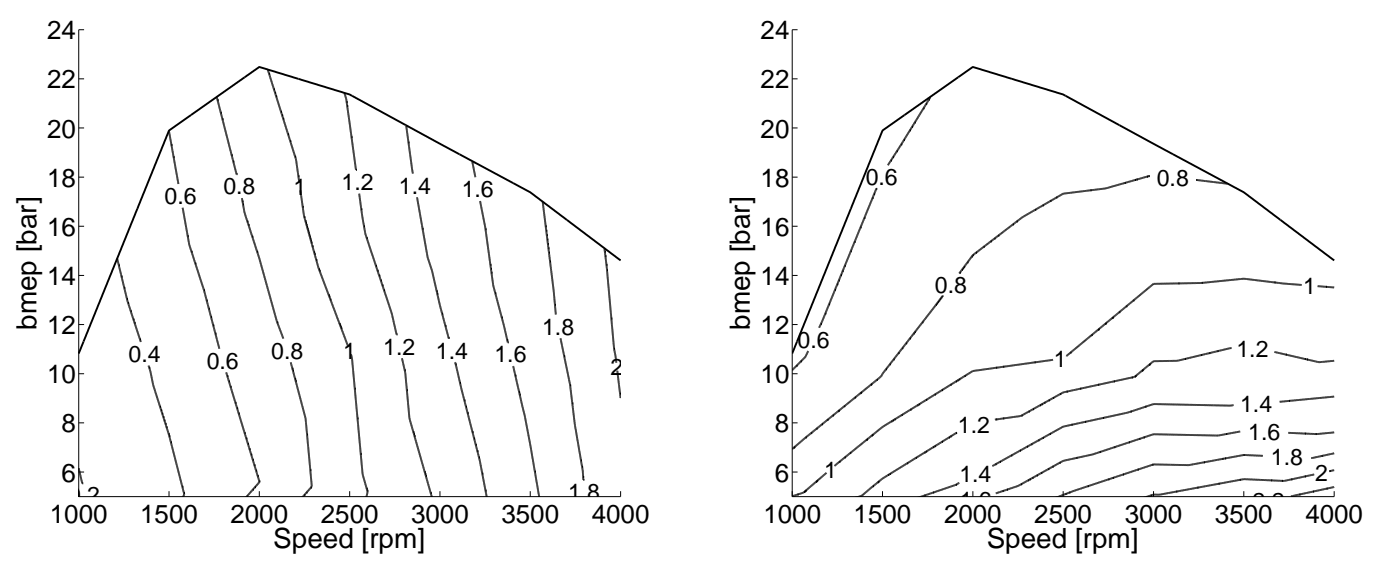

Figure 13: Friction in the bearings $\left(N_{f r}\right.$, bear $)$. Left: absolute value $(\mathrm{kW})$. Right: relative value $\left(\% \dot{m}_{f} H_{v}\right)$
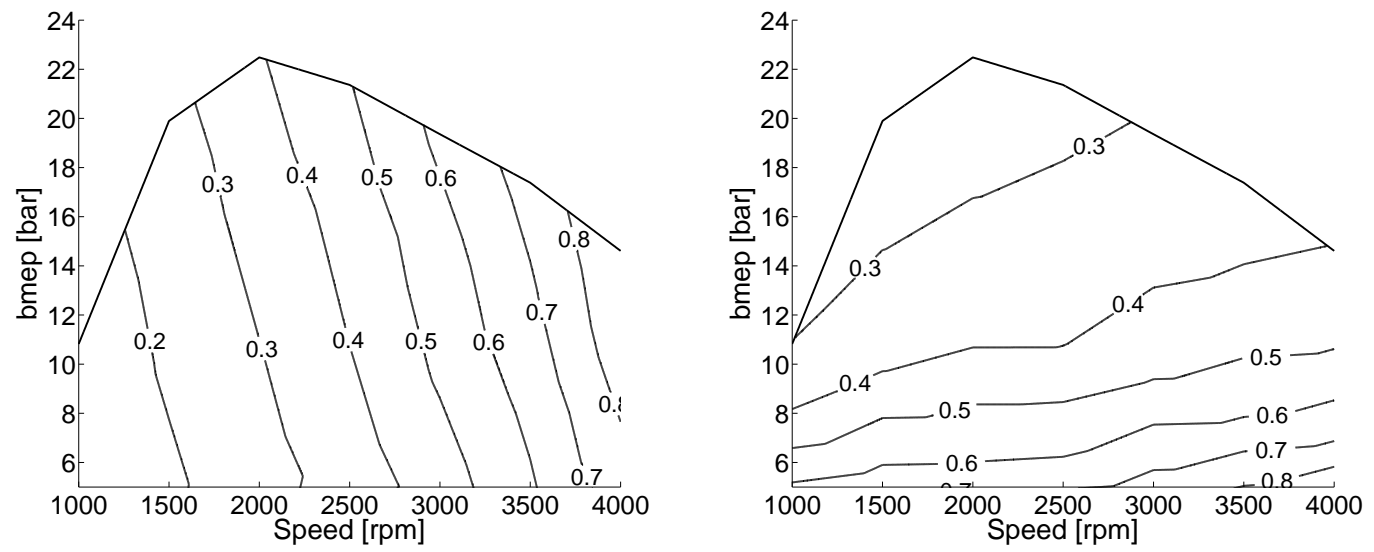

Figure 14: Friction in the valve train $\left(N_{f r, v a l v}\right)$. Left: absolute value $(\mathrm{kW})$. Right: relative value $\left(\%_{m_{f}} H_{v}\right)$ 

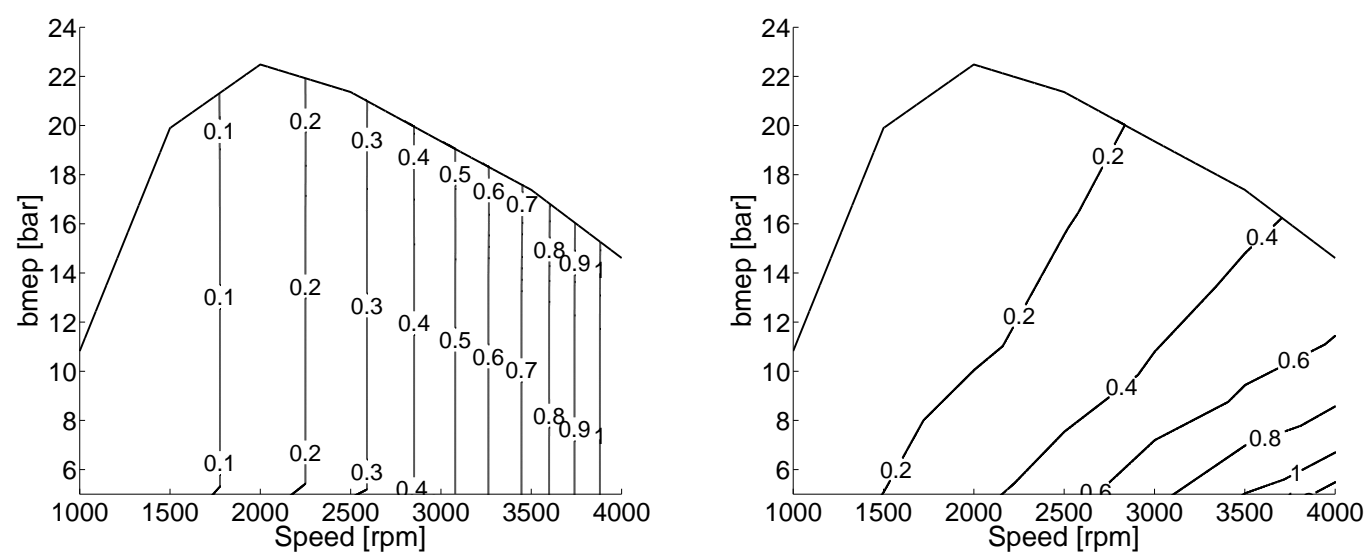

Figure 15: Coolant pump power $\left(N_{\text {cool }}\right)$. Left: absolute value $(\mathrm{kW})$. Right: relative value $\left(\% \dot{m}_{f} H_{v}\right)$
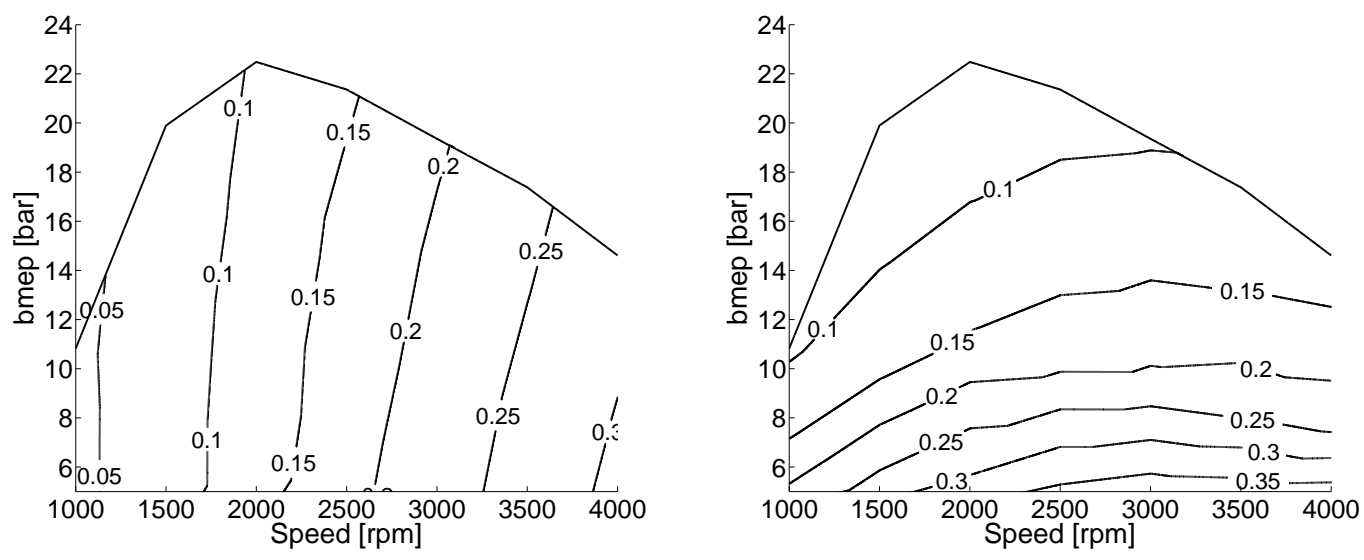

Figure 16: Oil pump power $\left(N_{\text {oil }}\right)$. Left: absolute value $(\mathrm{kW})$. Right: relative value $\left(\% \dot{m}_{f} H_{v}\right)$
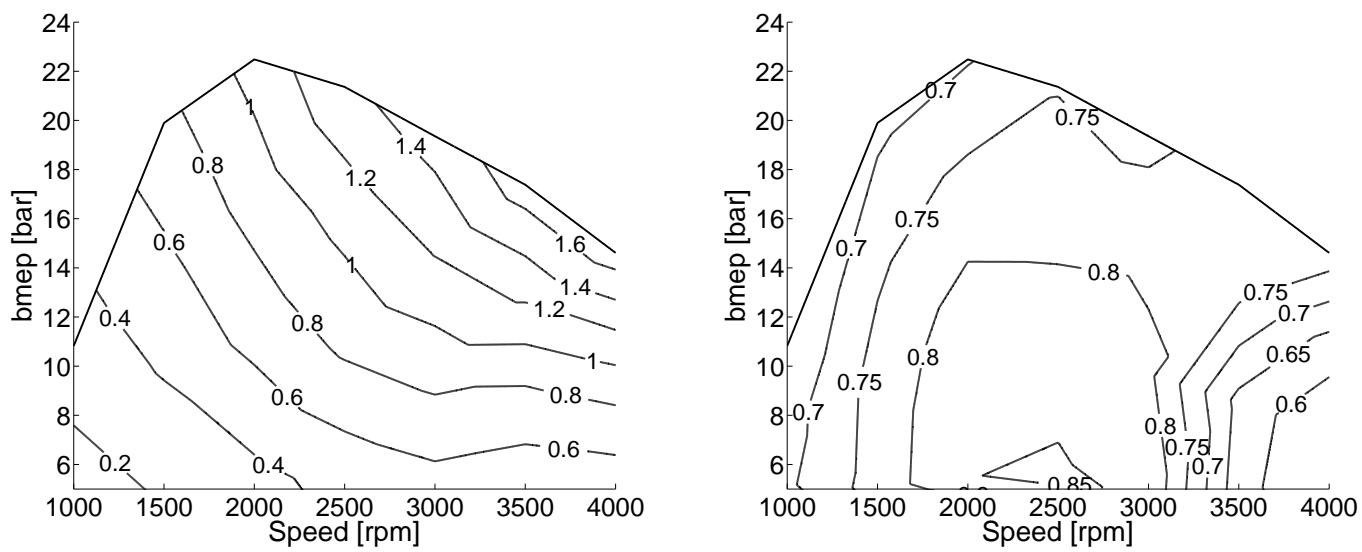

Figure 17: Fuel pump power $\left(N_{f}\right)$. Left: absolute value $(\mathrm{kW})$. Right: relative value $\left(\% \dot{m}_{f} H_{v}\right)$ 


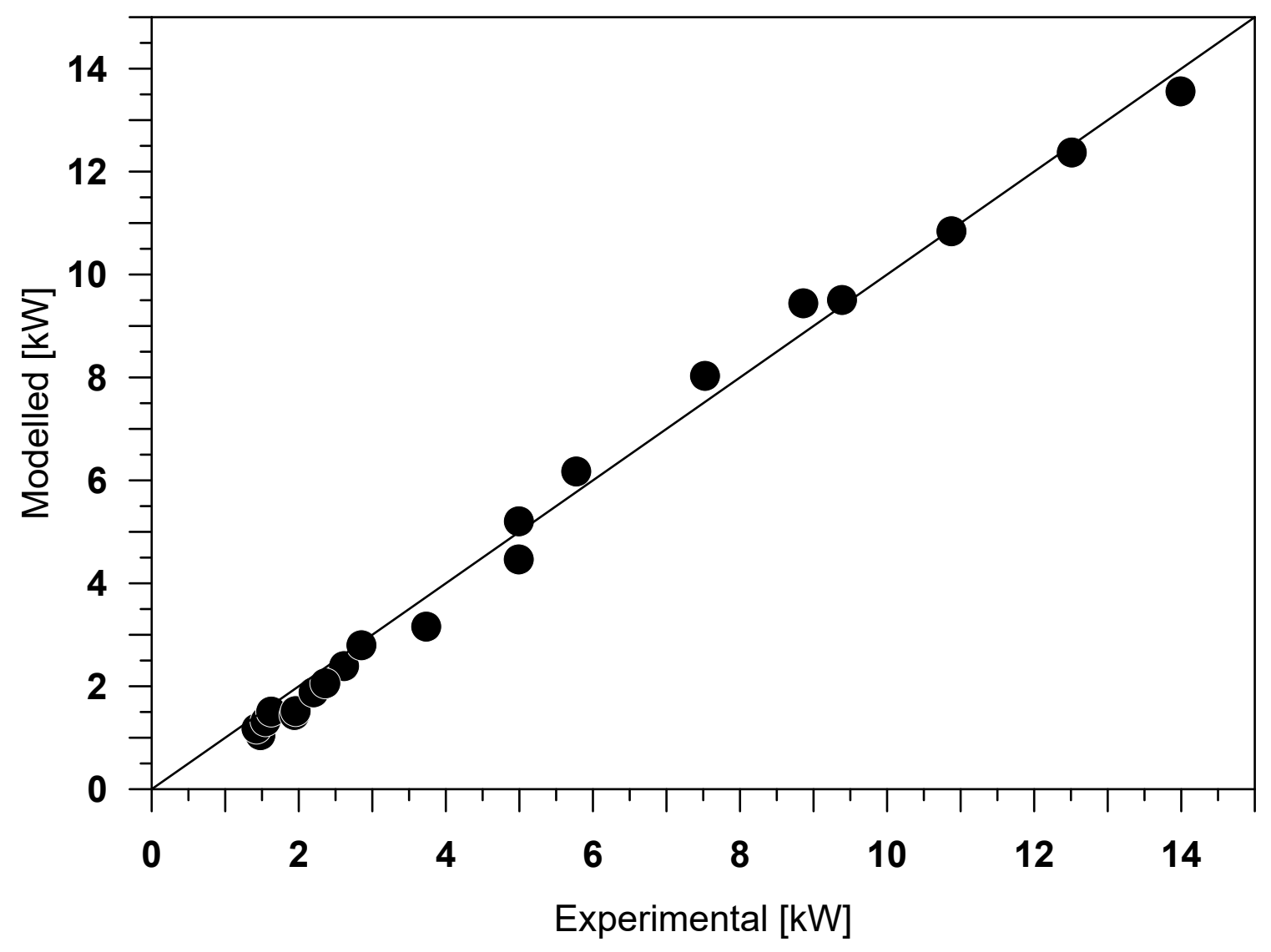

Figure 18: Evaluation of the adjustment in an engine with a roller follower 


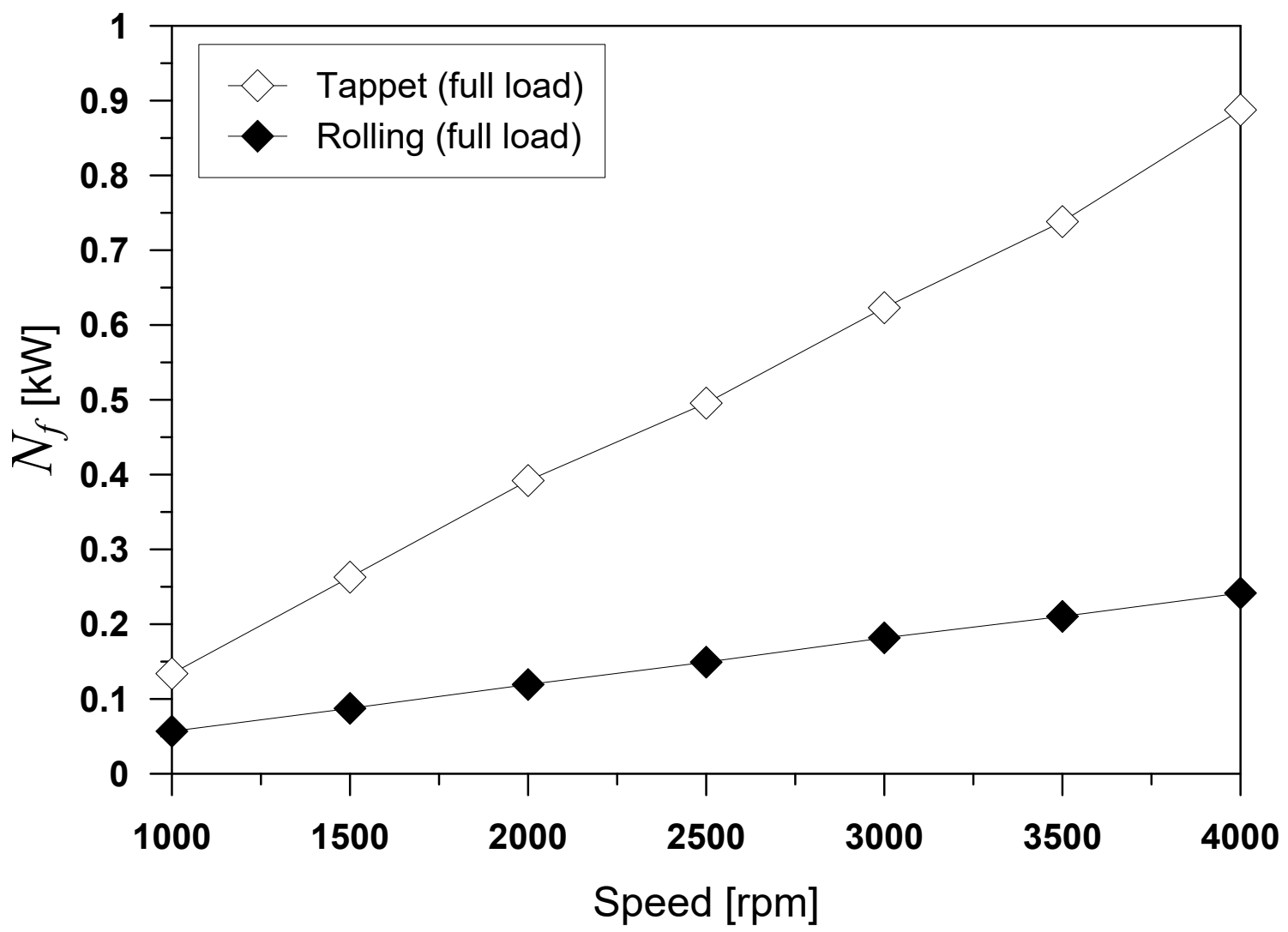

Figure 19: Evaluation of the improvements by using a rolling follower 


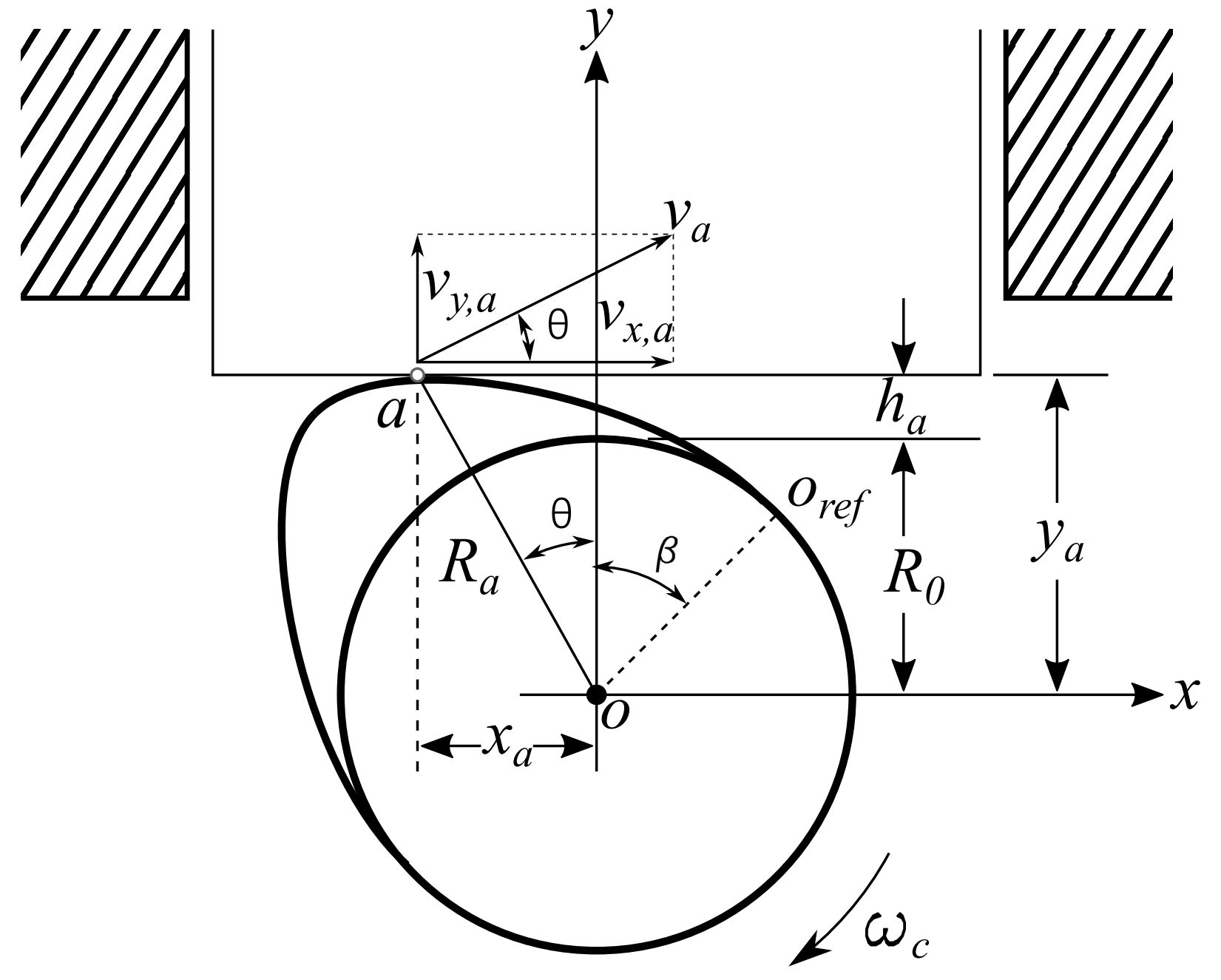

Figure 20: Cam/tappet kinematic scheme 


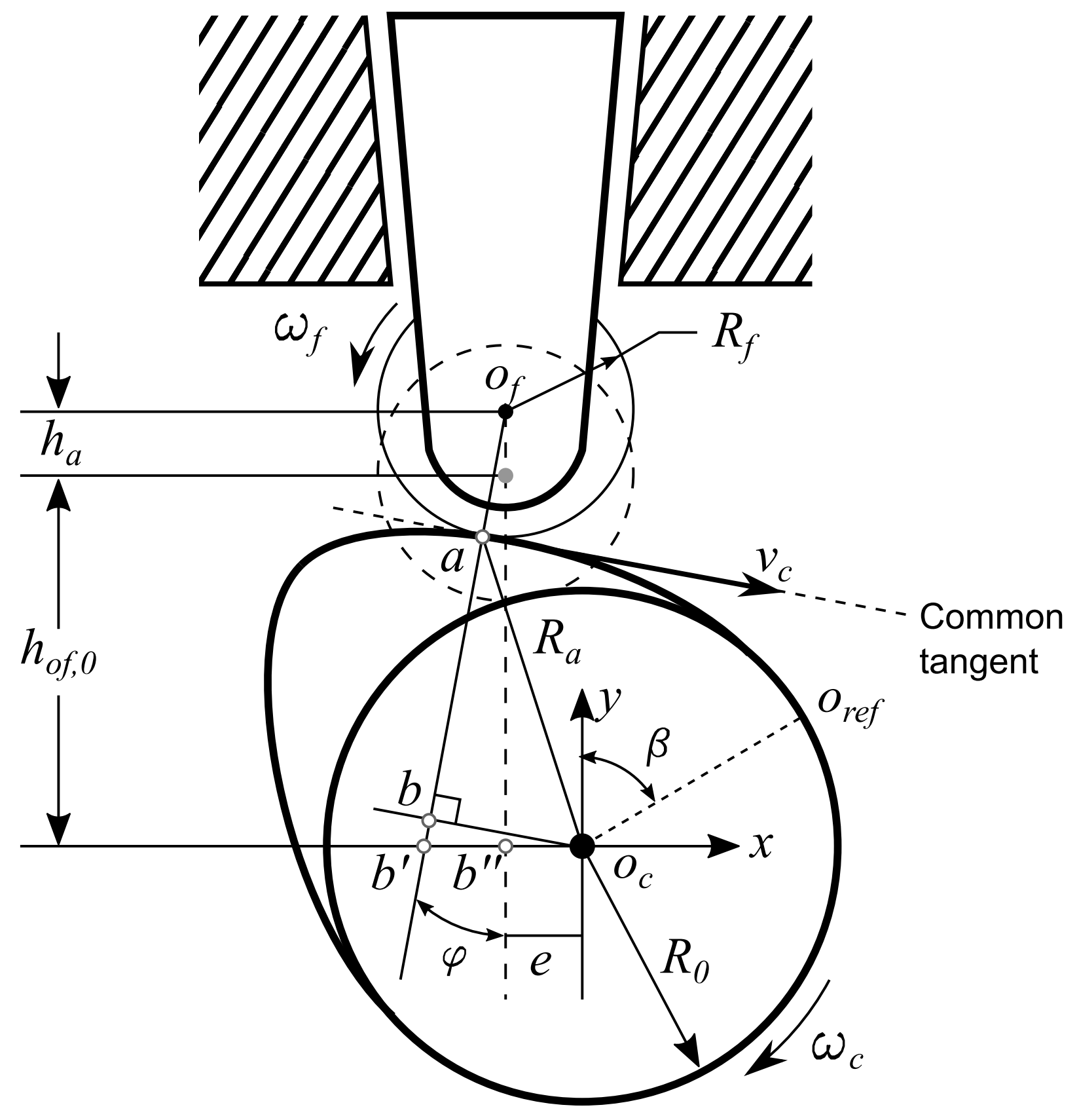

Figure 21: Cam/rolling follower kinematic scheme 

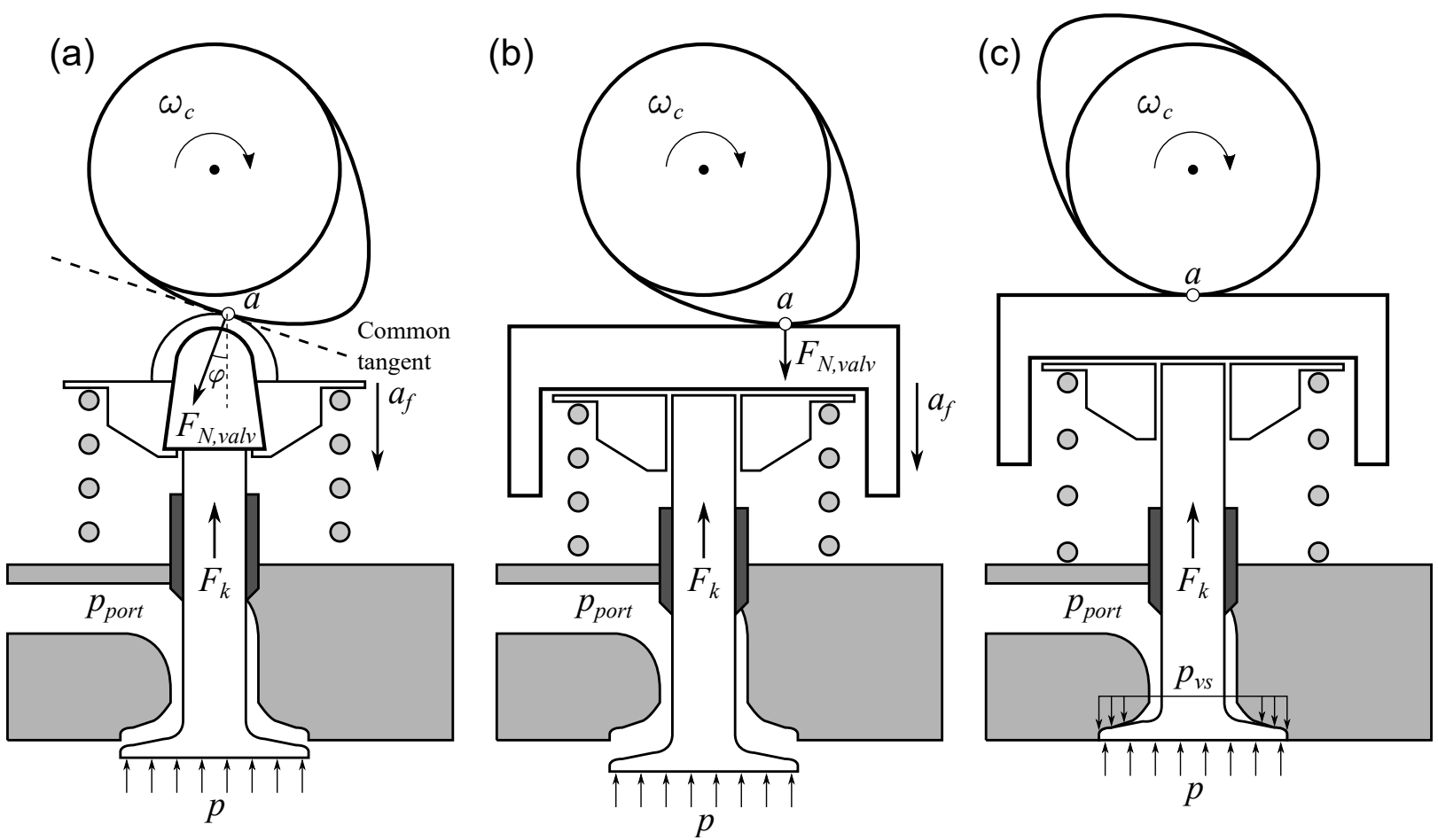

Figure 22: Cam/follower dynamic scheme 


\section{Appendix A. Kinematic and dynamic analysis of the valve train}

\section{Appendix A.1. Cam/Tappet follower kinematics}

In Figure 20, a schematic of the cam/tappet contact is presented. The speed of the contact point between the cam and tappet (point $a$ ), is determined as [46]:

$$
v_{a}=\omega_{c} R_{a}=\sqrt{v_{x, a}^{2}+v_{y, a}^{2}}
$$

where $\omega_{c}$ is the angular speed of the cam whose value is one half of the engine speed $\left(\omega_{c}=0.5 \omega\right)$ and $v_{a}$ is the speed of the point $a$, whose components $\left(v_{x, a}\right.$ and $\left.v_{y, a}\right)$ are geometrically determined as follows:

$$
\begin{aligned}
& v_{x, a}=\omega_{c}\left(R_{0}+h_{a}\right) \\
& v_{y, a}=\omega_{c} x_{a}
\end{aligned}
$$

where $R_{0}$ is the cam base radius, $h_{a}$ is the tappet lift and $R_{a}$ is the distance between the contact point and the cam centre. Through derivation the instantaneous tappet lift, the acceleration of the follower $\left(a_{v}\right)$ is obtained:

$$
a_{v}=\frac{\mathrm{d}^{2} h_{a}}{\mathrm{~d} t^{2}}=\omega_{c}^{2} \frac{\mathrm{d}^{2} h_{a}}{\mathrm{~d} \beta^{2}}
$$

where $\beta$ is the angular position of the cam with respect to the reference line $\left({o \sigma_{r}}_{-}\right)$, called also cam rotation angle.

Solving for $x_{a}$ in Equation (A.3), the following expression can be obtained:

$$
x_{a}=\frac{v_{y, a}}{\omega_{c}}=\frac{\mathrm{d} h_{a} / \mathrm{d} t}{\mathrm{~d} \beta / \mathrm{d} t}=\frac{\mathrm{d} h_{a}}{\mathrm{~d} \beta}
$$

therefore, the velocity of the cam/tappet contact point relative to the tappet $\left(v_{t}\right)$ can be determined through derivation of Equation (A.5) as follows:

$$
v_{t}=\frac{\mathrm{d} x_{a}}{\mathrm{~d} t}=\omega_{c} \frac{\mathrm{d} x_{a}}{\mathrm{~d} \beta}=\omega_{c} \frac{\mathrm{d}^{2} h_{a}}{\mathrm{~d} \beta^{2}}
$$

where $\mathrm{d}^{2} h_{a} / \mathrm{d} \beta^{2}$ is known as the geometrical acceleration of the follower, caused by the cam lift movement pattern.

The sliding velocity $\left(v_{s}\right)$ corresponds to the horizontal velocity of point $a$ observed by a static point in the tappet. Therefore, for a flat-tappet follower without tappet spin $v_{s}=v_{x, a}$. Taking this into account, the resultant contact velocity of the cam/tappet $\left(v_{c}\right)$ is expressed as the addition of $v_{s}$ and $v_{t}$ as follows [46]:

$$
v_{c}=v_{s}+v_{t}=\omega_{c}\left(R_{0}+h_{a}+\frac{\mathrm{d}^{2} h_{a}}{\mathrm{~d} \beta^{2}}\right)
$$


Note that the term in brackets correspond to the instantaneous radius of curvature of the cam $\left(R_{c}\right)$ [55]:

$$
R_{c}=R_{0}+h_{a}+\frac{\mathrm{d}^{2} h_{a}}{\mathrm{~d} \beta^{2}}
$$

Finally, to determine the tribological conditions between the cam and the tappet, it is necessary to calculate the instantaneous velocity of lubricant entrainment into the cam/tappet contact $\left(v_{e}\right)$, which is done as proposed in [46]:

$$
v_{e}=\frac{v_{c}+v_{t}}{2}=\frac{\omega_{c}}{2}\left(R_{0}+h_{a}+2 \frac{\mathrm{d}^{2} h_{a}}{\mathrm{~d} \beta^{2}}\right)
$$

\section{Appendix A.2. Cam/Rolling follower kinematics}

In Figure 21, a schematic of the cam/rolling follower contact is presented. The contact velocity $\left(v_{c}\right)$ can be expressed in terms of the follower roller angular speed $\left(\omega_{f}\right)$ and radius $\left(R_{f}\right)$ as:

$$
v_{c}=\omega_{f} R_{f}
$$

Since the cam angular speed $\left(\omega_{c}\right)$ can be directly correlated with the engine angular speed, it is interesting to express $v_{c}$ in terms of $\omega_{c}$ as:

$$
v_{c}=\omega_{c} \bar{a} b
$$

where $\overline{a b}$ is the distance between the contact pole $(b)$ and the contact point $(a)$, which are continuously changing during the cam rotation. This line can be determined through the geometrical correlation $\bar{a} b=a \bar{b}^{\prime}-b \bar{b}^{\prime}$, where $a \bar{b}^{\prime}$ is calculated by means of the analysis of the triangle $o_{f}-b^{\prime}-b^{\prime \prime}$ as:

$$
a \bar{b}^{\prime}=\frac{\left(h_{o_{f}, 0}+h_{a}\right)}{\cos \varphi}-R_{f}
$$

where $h_{o_{f}, 0}$ is the minimum height between the cam and follower centres when the valve is closed, which is determined from the $R_{f}, R_{c}$ and the eccentricity between cam and rolling follower centres $(e) . h_{a}$ is the valve lifting and $\varphi$ is the pressure angle. Similarly, $b \bar{b}^{\prime}$ is obtained by analysing the triangle $o_{c}-b-b^{\prime}$ as:

$$
b \bar{b}^{\prime}=\overline{o_{c}} b \tan \varphi
$$

where $\overline{o_{c}} b$ is determined through the following trigonometric expression:

$$
\overline{o_{c} b}=\overline{o_{c} b^{\prime}} \cos \varphi
$$

and $\overline{o_{c}} b^{\prime}$ is obtained by means of the triangle $o_{f}-b^{\prime}-b^{\prime \prime}$ as follows: 


$$
\begin{aligned}
\overline{o_{c} b^{\prime}} & =e+b^{\prime} \bar{b}^{\prime \prime} \\
& =e+\left(h_{o_{f}, 0}+h_{a}\right) \tan \varphi
\end{aligned}
$$

from which the pressure angle is attained as:

$$
\varphi=\tan ^{-1}\left(\frac{\mathrm{d} h_{a} / \mathrm{d} \beta-e}{h_{o_{f}, 0}+h_{a}}\right)
$$
Equations (A.12) and (A.17) as: to determine $\varphi$ (the rest of the parameters can be obtained from geometry).

$$
v_{b^{\prime}}=\omega_{c} \overline{o_{c} b^{\prime}}
$$

For convenience, Equation (A.19) can be rewritten as:

$$
\overline{o_{c}} \bar{b}^{\prime}=\frac{v_{b^{\prime}}}{\omega_{c}}=\frac{\mathrm{d} h_{a} / \mathrm{d} t}{\mathrm{~d} \beta / \mathrm{d} t}=\frac{\mathrm{d} h_{a}}{\mathrm{~d} \beta}
$$

$$
\frac{\mathrm{d} h_{a}}{\mathrm{~d} \beta}=e+\left(h_{o_{f}, 0}+h_{a}\right) \tan \varphi
$$

Therefore, $\bar{a} \bar{b}=a \bar{b}^{\prime}-b \bar{b}^{\prime}$ can be rewritten as a function of more convenient geometrical parameters by considering

$$
\overline{a b}=\frac{\left(h_{o_{f}, 0}+h_{a}\right)}{\cos \varphi}-R_{f}-e \sin \varphi-\left(h_{o_{f}, 0}+h_{a}\right) \sin \varphi \tan \varphi
$$

This last expression can be substituted in Equation (A.11) to obtain $v_{c}$. To solve this equation, it is also necessary

In Figure 21, it can be observed that the normal to the common tangent (line $\bar{a} \bar{b}$ ) intersects the $x$ axis in the point $b^{\prime}$, which corresponds to the instantaneous centre of rotation between cam and follower. Since the follower describes a translational motion along the $y$ axis, the lifting velocity can be determined as point $b^{\prime}$ velocity $\left(v_{b^{\prime}}\right)$ as:

Then, by combining Equations (A.15) and (A.20), the following expression can be obtained: 
From a tribological point of view, it is interesting to determine the instantaneous velocity of lubricant entrainment into the cam/tappet contact $\left(v_{e}\right)$. This velocity can be obtained as the average between the cam $\left(v_{c}\right)$ and the follower $\left(v_{f}\right)$ contact velocities [56]. Assuming that the roller follower rolls without slipping, $v_{c}$ must be equal as $v_{f}$, therefore the following relation can be obtained:

$$
\begin{aligned}
& v_{e}=0.5\left(v_{c}+v_{f}\right) \\
& v_{e}=v_{c}
\end{aligned}
$$

Note that the model is written as a function of the cam rotation angle $\beta$ which can be expressed in terms of the crank angle $\alpha$, considering that the cam have twice the angular speed of the crankshaft in 4-stroke engines, and the same angular speed in 2-stroke engines. This relationship is useful to determine the friction over an engine cycle.

\section{Appendix A.3. Cam/follower dynamics}

In this work it is assumed that the follower rod is the valve rod itself. In Figure 22, the forces acting in a rolling follower and in a bucket tappet follower are presented.

In the more general case of a roller follower (Figure 22 (a)), when the valve is open, the force normal to the common tangent $\left(F_{N, v a l v}\right)$ can be determined through $\sum F_{y}=m a$ as:

$$
\begin{aligned}
F_{N, v a l v} \cos \varphi & =A_{v}\left(p-p_{\text {port }}\right)+F_{k}-\left(m_{v} a_{v}+m_{s} a_{s}\right) \\
F_{N, \text { val }} & =\frac{1}{\cos \varphi}\left[A_{v}\left(p-p_{\text {port }}\right)+F_{k}-\left(m_{v} a_{v}+m_{s} a_{s}\right)\right]
\end{aligned}
$$

where $a_{v}$ and $a_{s}=a_{v} / 2$ are the valve and the spring centre of mass accelerations, $m_{v}$ and $m_{s}$ are the valve and spring masses, $p$ is the in-cylinder pressure, $p_{\text {port }}$ is the port pressure (which is equal to the intake or exhaust pressure depending on the valve analysed) and $F_{k}$ is the spring force, which is calculated as:

$$
F_{k}=F_{k, 0}+k_{s} h_{a}
$$

being $F_{k, 0}$ the spring pre-load, $k_{s}$ the spring constant and $h_{a}$ the spring displacement from the initial position.

In the case of tappet followers (Figure 22 (b)), the common tangent is parallel to the tappet surface, thus $\varphi=0$ and hence Equation (A.24) becomes:

$$
F_{N, v a l v}=A_{v}\left(p-p_{\text {port }}\right)+F_{k}-\left(m_{v} a_{v}+m_{s} a_{s}\right)
$$

When the valve is closed (Figure 22 (c)), three main observations have to be made: 
- The valve and spring masses are stopped, thus no inertial loads are exerted.

- The force due to the chamber and port pressures $\left(A_{v}\left(p-p_{p o r t}\right)\right)$ is supported in the valve seat.

- The contact between cam and follower should be minimum, thus a very low normal force is exerted in this contact point.

Taking these comments into account, it can be assumed that when the valve is in contact with the valve seat, there is no normal force exerted between cam and follower and the friction is negligible. 


\section{References}

[1] B. Mohan, W. Yang, S. Chou, Fuel injection strategies for performance improvement and emissions reduction in compression ignition engines - A Review, Renewable and Sustainable Energy Reviews 28 (2013) 664-676. doi:10.1016/j.rser.2013.08.051.

[2] M. Canakci, Combustion characteristics of a DI-HCCI gasoline engine running at different boost pressures, Fuel 96 (2012) 546-555. doi:10.1016/j.fuel.2012.01.042.

[3] P. Michel, A. Charlet, G. Colin, Y. Chamaillard, G. Bloch, C. Nouillant, Optimizing fuel consumption and pollutant emissions of gasolineHEV with catalytic converter, Control Engineering Practicedoi:10.1016/j.conengprac.2015.12.010.

[4] M. Pietikäinen, A. Väliheikki, K. Oravisjärvi, T. Kolli, M. Huuhtanen, S. Niemi, S. Virtanen, T. Karhu, R. Keiski, Particle and NOx emissions of a non-road diesel engine with an SCR unit: The effect of fuel, Renewable Energy 77 (2015) 377-385. doi:10.1016/j.renene.2014.12.031.

[5] C. Beatrice, S. Di Iorio, C. Guido, P. Napolitano, Detailed characterization of particulate emissions of an automotive catalyzed DPF using actual regeneration strategies, Experimental Thermal and Fluid Science 39 (2012) 45-53. doi:10.1016/j.expthermflusci.2012.01.005.

[6] V. Bermúdez, J. Luján, P. Piqueras, D. Campos, Pollutants emission and particle behavior in a pre-turbo aftertreatment light-duty diesel engine, Energy 66 (2014) 509-522. doi:10.1016/j.energy.2014.02.004.

[7] P. European, Regulation (EU) No 333/2014 of the European Parliament and of the Council of 11 March 2014 amending Regulation (EC) No 443/2009 to define the modalities for reaching the 2020 target to reduce CO2 emissions from new passenger cars, Official Journal of the European Union L103 Vol 5 (2014) 15-21.

[8] G. Parvate-Patil, H. Hong, B. Gordon, An assessment of intake and exhaust philosophies for variable valve timing, SAE Technical Paper 2003-32-0078doi:10.4271/2003-32-0078.

[9] F. Payri, P. Olmeda, J. Martín, R. Carreño, Experimental analysis of the global energy balance in a DI diesel engine, Applied Thermal Engineering 89 (2015) 545-557. doi:10.1016/j.applthermaleng.2015.06.005.

[10] D. Taraza, N. Henein, Friction Losses in Multi-Cylinder Diesel Engines, SAE Technical Paper 2000-01-0921.

[11] K. Holmberg, P. Andersson, A. Erdemir, Global energy consumption due to friction in passenger cars, Tribology International 47 (2012) 221-234. doi:10.1016/j.triboint.2011.11.022.

[12] U. Morawitz, J. Mehring, L. Schramm, Benefits of Thermal Spray Coatings in Internal Combustion Engines, with Specific View on Friction Reduction and Thermal Management, SAE Technical Paper 2013-01-0292doi:10.4271/2013-01-0292.

[13] M. De Carvalho, P. Seidl, C. Belchior, J. Sodré, Lubricant viscosity and viscosity improver additive effects on diesel fuel economy, Tribology International 43 (12) (2010) 2298-2302. doi:10.1016/j.triboint.2010.07.014.

[14] V. Macián, B. Tormos, V. Bermúdez, L. Ramírez, Assessment of the effect of low viscosity oils usage on a light duty diesel engine fuel consumption in stationary and transient conditions, Tribology International 79 (2014) 132-139. doi:10.1016/j.triboint.2014.06.003.

[15] M. Hoshi, Reducing friction losses in automobile engines, Tribology International 17 (4) (1984) 185-189. doi:10.1016/0301-679X(84)900173.

[16] I. Etsion, E. Sher, Improving fuel efficiency with laser surface textured piston rings, Tribology International 42 (4) (2009) $542-547$. doi:10.1016/j.triboint.2008.02.015.

[17] M. Okamoto, I. Sakai, Contact Pressure Distribution of Piston Rings -Calculation Based on Piston Ring Contour -, SAE Techinical Paper 2001-01-0571doi:10.4271/2001-01-0571.

[18] V. Korte, T. Glas, M. Lettmann, W. Krepulat, C. Steinmetz, Cam Roller Follower Design for Heavy Duty Diesel Engines, SAE Technical Paper 2000-01-0525.

[19] T. Muhr, New Technologies for Engine Valve Springs, SAE Techinical Paper 930912doi:10.4271/930912.

[20] H. Pang, C. Brace, Review of engine cooling technologies for modern engines, Proc. Inst. Mech. Engrs. 218 (11) (2004) $1209-1215$. doi:10.1243/0954407042580110.

[21] M. Lasecki, J. Cousineau, Controllable Electric Oil Pumps in Heavy Duty Diesel Engines, SAE Techinical Paper 2003-013421doi:10.4271/2003-01-3421. 
[22] M. De Cesare, M. Parotto, F. Covassin, S. Sgatti, Electric Low Pressure Fuel Pump Control for Fuel Saving, SAE Techinical Paper 2013-010339doi: 10.4271/2013-01-0339.

[23] J. Meira, E. Ribeiro, A. Filho, W. Melo, Strategies for energy savings with use of constant and variable oil pump systems, SAE Techinical Paper 2011-36-0150doi:10.4271/2011-36-0150.

[24] D. Allen, M. Lasecki, Thermal Management Evolution and Controlled Coolant Flow, SAE Techinical Paper 2001-01-1732doi:10.4271/2001$01-1732$

[25] K. Robinson, J. Hawley, N. Campbell, D. Tilley, A Review of Precision Engine Cooling, SAE Techinical Paper 1999-010578doi:10.4271/1999-01-0578.

[26] F. Payri, J. Luján, J. Martín, A. Abbad, Digital signal processing of in-cylinder pressure for combustion diagnosis of internal combustion engines, Mechanical Systems and Signal Processing 24 (6) (2010) 1767-1784. doi:10.1016/j.ymssp.2009.12.011.

[27] J. Tichý, G. Gautschi, Elektrische Meßtechnik, Springer, Berlin, 1980.

[28] J. Benajes, P. Olmeda, J. Martín, R. Carreño, A new methodology for uncertainties characterization in combustion diagnosis and thermodynamic modelling, Applied Thermal Engineering 71 (2014) 389-399. doi:10.1016/j.applthermaleng.2014.07.010.

[29] F. Payri, P. Olmeda, J. Martín, R. Carreño, A New Tool to Perform Global Energy Balances in DI Diesel Engines, SAE Int. J. Engines 7 (1) (2014) 43-59. doi:10.4271/2014-01-0665.

[30] X. Ye, G. Chen, M. Luo, Y. Jiang, Design and Control of Diesel and Natural Gas Engines for Industrial and Rail Transportation Applicationsdoi:10.1115/ICEF2003-0735.

[31] T. Tian, Dynamic behaviours of piston rings and their practical impact. part 1: Ring flutter and ring collapse and their effects on gas flow and oil transport, Proceedings of the Institution of Mechanical Engineers, Part J: Journal of Engineering Tribology 216 (4) (2002) $209-228$. arXiv:https://doi.org/10.1243/135065002760199961, doi:10.1243/135065002760199961.

URL https : //doi .org/10.1243/135065002760199961

[32] T. Ortjohann, A. Voncken, S. Pischinger, Piston ring dynamics simulation based on fea software, MTZ worldwide 69 (12) (2008) 36-41. doi:10.1007/BF03226936. URL https : //doi.org/10.1007/BF03226936

[33] P. C. Mishra, Modeling the root causes of engine friction loss: Transient elastohydrodynamics of a piston subsystem and cylinder liner lubricated contact, Applied Mathematical Modelling 39 (8) (2015) 2234 - 2260. doi:https://doi.org/10.1016/j.apm.2014.10.011. URL http: //wWw.sciencedirect.com/science/article/pii/S0307904X14004831

[34] P. Lyubarskyy, D. Bartel, 2d cfd-model of the piston assembly in a diesel engine for the analysis of piston ring dynamics, mass transport and friction, Tribology International 104 (Supplement C) (2016) 352 - 368. doi:https://doi.org/10.1016/j.triboint.2016.09.017. URL http://www.sciencedirect.com/science/article/pii/S0301679x 16303243

[35] R. Stanley, D. Taraza, N. Henein, A Simplified Friction Model of the Piston Ring Assembly, SAE Technical Paper 1999-010974doi:10.4271/1999-01-0974.

[36] R. Carreño Arango, A comprehensive methodology to analyse the Global Energy Balance in Reciprocating Internal Combustion Engines, Ph.D. thesis, Universitat Politècnica de València (2016).

[37] Federal-Mogul, Goetze Piston Ring Handbook (online resource) (2008). URL http: //korihandbook. federalmogul.com/en/

[38] C. Taylor, Engine Tribology, Elsevier, 1997. doi:10.1016/S0301-679X(97)86356-6.

[39] F. Payri, D. J.M., Motores de combustión interna alternativos, Reverté, Barcelona, 2011.

[40] A. Cameron, Basic Lubrication Theory, Longman, New York, 1971.

[41] M. Teodorescu, D. Taraza, N. Henein, W. Bryzik, Experimental Analysis of Dynamics and Friction in Valve Train Systems, SAE Technical Paper 2002-01-0484doi:10.4271/2002-01-0484.

[42] D. Beloiu, Modeling and Analysis of Valve Train , Part I - Conventional Systems, SAE Technical paper 2010-01-1198doi:10.4271/2010-011198. 
[43] N. Nayak, P. Lakshminarayanan, M. Babu, A. Dani, Predictions of cam follower wear in diesel engines, Wear 260 (1-2) (2006) 181-192. doi:10.1016/j.wear.2005.02.022.

[44] D. Dowson, G. Higginson, Elastohydrodynamic Lubrication, SI Edition, Pergamon press, Oxford, 1977.

[45] M. Teodorescu, D. Taraza, N. Henein, W. Bryzik, Simplified Elasto-Hydrodynamic Friction Model of the Cam-Tappet Contact, SAE Techinical Paper 2003-01-0985doi:10.4271/2003-01-0985.

[46] J. Guo, W. Zhang, D. Zou, Investigation of dynamic characteristics of a valve train system, Mechanism and Machine Theory 46 (12) (2011) 1950-1969. doi:10.1016/j.mechmachtheory.2011.07.014.

[47] J. Greenwood, J. Tripp, The Contact of Two Nominally Flat Rough Surfaces, Proc. Instn. Mech. Engrs 185 (1970) 625-633. doi:10.1243/PIME_PROC_1970_185_069_02.

[48] M. Teodorescu, M. Kushwaha, H. Rahnejat, D. Taraza, Elastodynamic transient analysis of a four-cylinder valvetrain system with camshaft flexibility, Proceedings of the Institution of Mechanical Engineers, Part K: Journal of Multi-body Dynamics 219 (1) (2005) 13-25. doi:10.1243/146441905X9962.

[49] P. Goksem, R. Hargreaves, The effect of viscous shear heating on both film thickess and rolling traction in a EHL line contact. Part I: Fully flooded conditions, ASME. J. of Lubrication Tech. 100 (3) (1978) 346-352. doi:10.1115/1.3453183.

[50] M. Calabretta, D. Cacciatore, P. Carden, Valvetrain Friction - Modeling, Analysis and Measurement of a High Performance Engine Valvetrain System, SAE Int. J. Engines 3 (2) (2010) 72-84. doi:10.4271/2010-01-1492.

[51] L. Moody, An approximate formula for pipe friction factors, Trans. ASME 69 (12) (1947) 1005-1011.

[52] D. Kouremenos, C. Rakopoulos, D. Hountalas, T. Zannis, Development of a Detailed Friction Model to Predict Mechanical Losses at Elevated Maximum Combustion Pressures, SAE Technical Paper 2001-01-0333doi:10.4271/2001-01-0333.

[53] J. Heywood, Internal Combustion Engines Fundamentals, McGraw-Hill, New York, 1988.

[54] A. Comfort, An Introduction to Heavy-Duty Diesel Engine Frictional Losses And Lubricant Properties Affecting Fuel Economy - Part I, SAE Technical Paper 2003-01-3225doi:10.4271/2003-01-3225.

[55] J. Shigley, J. Uicker, Theory of Machines and Mechanisms, international Edition, McGraw-Hill, ISBN 0-07-Y66560-5, Singapore, 1981.

[56] J. Lee, D. Patterson, Analysis of Cam/Roller Follower Friction and Slippage in Valve Train Systems, SAE Technical paper 951039doi:10.4271/951039. 